\title{
Recent Advances in Solid Catalysts Obtained by Metalloporphyrins Immobilization on Layered Anionic Exchangers: A Short Review and Some New Catalytic Results
}

\author{
Shirley Nakagaki ${ }^{1, *}$, Karen Mary Mantovani ${ }^{1}$, Guilherme Sippel Machado ${ }^{1,2}$, \\ Kelly Aparecida Dias de Freitas Castro ${ }^{1,3}$ and Fernando Wypych ${ }^{1}$ \\ 1 Laboratório de Bioinorgânica e Catálise, Departamento de Química, Centro Politécnico, \\ Universidade Federal do Paraná (UFPR), Curitiba, Paraná 81531-990, Brazil; \\ karen.mary16@gmail.com (K.M.M.); guismachado@yahoo.com.br (G.S.M.); \\ kedc2000@yahoo.com.br (K.A.D.F.C.); wypych@ufpr.br (F.W.) \\ 2 Centro de Estudos do Mar, Pontal do Paraná, Paraná, Universidade Federal do Paraná (UFPR), \\ Paraná 83255-000, Brazil \\ 3 Departamento de Química e QOPNA, Universidade de Aveiro, Aveiro 3810-193, Portugal \\ * Correspondence: shirleyn@ufpr.br; Tel.: +55-041-33613180
}

Academic Editors: M. Graça P. M. S. Neves and M. Amparo F. Faustino

Received: 13 January 2016 ; Accepted: 24 February 2016 ; Published: 29 February 2016

\begin{abstract}
Layered materials are a very interesting class of compounds obtained by stacking of two-dimensional layers along the basal axis. A remarkable property of these materials is their capacity to interact with a variety of chemical species, irrespective of their charge (neutral, cationic or anionic). These species can be grafted onto the surface of the layered materials or intercalated between the layers, to expand or contract the interlayer distance. Metalloporphyrins, which are typically soluble oxidation catalysts, are examples of molecules that can interact with layered materials. This work presents a short review of the studies involving metalloporphyrin immobilization on two different anionic exchangers, Layered Double Hydroxides (LDHs) and Layered Hydroxide Salts (LHSs), published over the past year. After immobilization of anionic porphyrins, the resulting solids behave as reusable catalysts for heterogeneous oxidation processes. Although a large number of publications involving metalloporphyrin immobilization on LDHs exist, only a few papers have dealt with LHSs as supports, so metalloporphyrins immobilized on LHSs represent a new and promising research field. This work also describes new results on an anionic manganese porphyrin (MnP) immobilized on Mg/Al-LDH solids with different nominal Mg/Al molar ratios (2:1, 3:1 and 4:1) and intercalated with different anions $\left(\mathrm{CO}_{3}{ }^{2-}\right.$ or $\left.\mathrm{NO}_{3}{ }^{-}\right)$. The influence of the support composition on the MnP immobilization rates and the catalytic performance of the resulting solid in cyclooctene oxidation reactions will be reported.
\end{abstract}

Keywords: porphyrin; oxidation; layered double hydroxides; layered hydroxide salts; immobilization; heterogeneous catalysis

\section{Introduction}

\subsection{Metalloporphyrins and Homogeneous Catalysis}

Porphyrins are highly conjugated heterocyclic macrocycles derived from four pyrrole rings interconnected by four methine bridges [1]. The chemical and physical properties of these compounds 
allow for their use in various fields [1,2]. In fact, porphyrins have promising medicinal [3] and catalytic [4] applications.

Porphyrin macrocycles can coordinate different catalytically active metals, like iron, copper, and nickel, among others. The catalytic use of the resulting metal complex will depend on the selected metal. Metalloporphyrins (MPs) occur in the nuclei of several oxidation enzymes such as cytochromes P450 [5,6], peroxidases [6], and catalases; they are often employed as model catalysts [7].

The great versatility of reactions catalyzed by $\mathrm{P} 450$ biomimetic systems; e.g., alkane hydroxylation and olefin epoxidation, regio- and stereo-selective reactions, and drug metabolism, has motivated researchers to develop new porphyrin derivatives $[8,9]$.

Groves [10] performed the pioneered studies on MPs as catalysts and showed that the $\mathrm{Fe}^{3+}$ complex $[\mathrm{Fe}(\mathrm{TPP}) \mathrm{Cl}]$ can mimic cytochrome $\mathrm{P} 450$ in many reactions, mainly hydroxylation and epoxidation, which boosted research in this field $[4,5,8]$.

MPs can efficiently and selectively catalyze a series of oxidation reactions in homogeneous medium (i.e., when the catalyst, substrate, and products are in the same phase). However, depending on the porphyrin structure, secondary reactions (MP destructive oxidation by other previously activated MP and secondary MP-MP interaction reaction; e.g., MP dimerization by $\mu$-oxo bridges) may take place in homogeneous medium, to deactivate the catalytic species [11,12]. Moreover, homogeneous systems preclude catalyst recovery and reuse $[13,14]$.

To overcome these common issues in homogeneous medium, various research groups have attempted to design catalysts for heterogeneous processes by immobilizing MPs on inorganic or organic solid supports [11,15-18]. MP immobilization should facilitate catalyst recovery and reuse as well as minimize destructive oxidation and other deactivating processes, ultimately preventing catalyst efficiency loss.

A variety of solid matrixes can serve as supports for MPs; for example, silicas, zeolites, polymeric nanoparticles, dendrimers, natural and synthetic layered hydroxides, and fibrous compounds, among others.

\subsection{Metalloporphyrins and Heterogeneous Catalysis}

In 1983, van der Made and co-workers [15] published one of the first reports on MP immobilization with a view to stabilizing the MP complex and promoting catalyst recycling; the catalyst support consisted of a polymeric matrix. These researchers realized that isolating the MP active site by immobilizing a $\mathrm{MnP}$ on a polymer support (isocyanide) was possible and avoided formation of the less reactive dimers observed during homogeneous catalysis. In fact, the immobilized $\mathrm{MnP}$ was three times more active for cyclohexene epoxidation than the free $\mathrm{MnP}$ [15].

Since then, a large number of inorganic solids have been studied as supports for MPs and many other complexes for catalytic purposes. Examples of these solids include clay minerals [19-21], silica [22,23], and metal oxides [24,25], among others [26]. Besides, polymeric matrixes like isocyanide [15], poly(vinyl alcohol) [27], and polystyrene [28] have also been employed to immobilize MPs and obtain efficient catalysts for oxidation reactions.

MP immobilization can also avoid the undesired approach between catalytic species and the consequent catalyst destruction. Moreover, proper combination of MP and support mimics the protein cavity of the natural enzyme and modulates specific selectivity for various catalytic reactions $[19,29]$.

Facile catalyst recovery from the heterogeneous catalytic reaction solution is among the advantages of catalyst immobilization and enables catalyst recycling. Catalyst recovery often demands just simple filtration or centrifugation [11,19].

In this context, layered double hydroxides (LDHs) and layered hydroxide salts (LHSs) have emerged as interesting supports to immobilize MPs. These matrixes are easy to obtain by one-pot synthesis, and their variable chemical composition is based on environmentally friendly elements. Additionally, they have layered morphology, controllable particle size, inertia in different experimental conditions, and low cost. 
Layered compounds can interact with MPs not only at the crystal basal surface, but also at the crystal edge. MPs can even intercalate between the matrix layers. All these alternatives expand the applicability of this class of compounds. When MPs intercalate between LDH or LHS layers [30-32], the resulting solid displays distinct and unusual selectivity as compared to the catalyst in solution (homogeneous catalysis) or even to the MP immobilized on the layered compound surface [33,34].

This short review offers a brief overview of the articles about MP immobilization on two different layered compounds, LDHs and LHSs, published over the past years. It also includes new data for an MP immobilized on different Mg/Al-LDHs.

\subsection{Layered Compounds}

Layered compounds are part of an unusual class of compounds obtained by packing of two-dimensional units (layers) along the basal crystallographic axis. These compounds have called researchers' attention over the last years mainly because it is possible manipulate single layers, but this manipulation is not possible on the traditional tridimensional materials.

Depending on the layer charges, layered compounds of synthetic or natural origin can be classified into neutral, positive, or negative. These charges will depend on the material that is present during the genesis or the oxi-reduction process in which the metal cation undergoes oxidation or reduction, to intercalate cations or anions, respectively [35]. In some examples, neutral species can also intercalate between the layers by just breaking the bonds that hold the layers together (e.g., kaolinite intercalated with different neutral molecules).

The layer thickness will depend on the material used to prepare the layered compound, and the material may be one-, three-, or seven-atom-thick as in the case of graphite, transition metal dichalcogenides, and 2:1 cationic exchange clay minerals or micas, respectively.

Anionic Exchange layered compounds are rare in nature, but it is possible to obtain countless compounds of this type in the laboratory by using simple synthetic procedures. Most of these compounds are based on the Brucite structure $\left(\mathrm{Mg}(\mathrm{OH})_{2}\right)$, which is common for calcium, manganese, iron, cobalt, and nickel hydroxides, all of which bear a double positive charge.

The Brucite structure consists of layers of slightly distorted octahedra. In the center of these octahedral $\mathrm{Mg}^{2+}$, cations are coordinated with six hydroxyl groups occupying the vertices of the octahedra. In turn, each hydroxyl group coordinates with three $\mathrm{Mg}^{2+}$ cations, to generate a tri-octahedral structure where all the octahedral sites of the structure are filled. The octahedral unit shares vertices with three adjacent octahedra connected by the corners (Figure 1) the 2+ charge of the $\mathrm{Mg}^{2+}$ cation is shared by six bonds with the hydroxyls, to give a charge of $(1 / 3)+$. Because three $\mathrm{Mg}^{2+}$ bonds share the single charge on hydroxyl, the result is $(1 / 3)-$. Therefore, the $(1 / 3)+$ and $(1 / 3)-$ charges will cancel each other out [36,37].
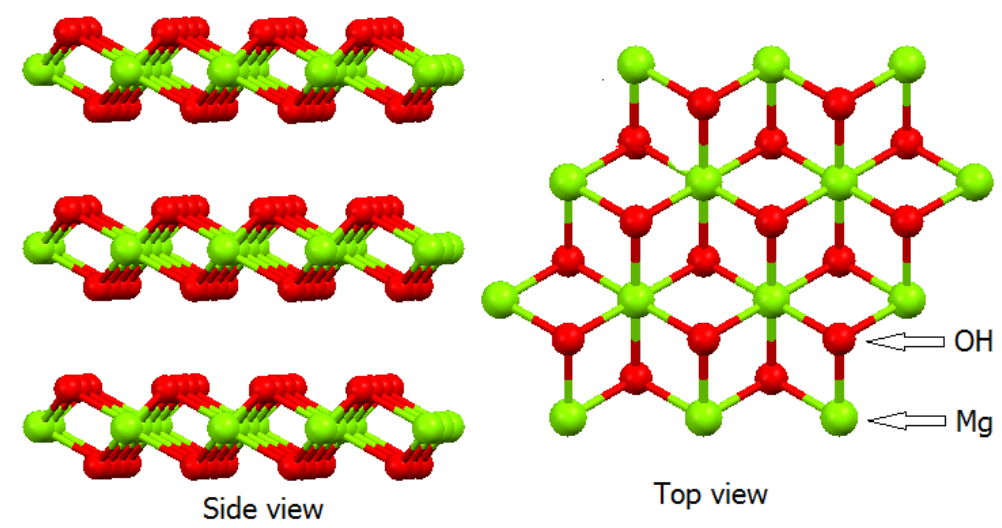

Top view

Figure 1. Brucite structure. Hydrogen atoms were removed from the structure to facilitate visualization $[36,37]$. 
Another common example of simple hydroxide is Gibbsite $\left(\mathrm{Al}(\mathrm{OH})_{3}\right)$. Because Gibbsite contains $\mathrm{Al}^{3+}$ in its structure, one third of the octahedral positions remain unoccupied, to ensure structural neutrality. This arrangement gives rise to the structure called di-octahedral. Charge balance for these structures is based on the Pauling electrostatic valence theory, which postulates that each cation present in the polyhedra tends to compensate the electric charge of each anion in stable coordinated structures. These layers bind to each other by Van der Waals forces. This interaction furnishes three-dimensional crystals that tend to grow preferentially along the layer planes, to afford crystals with plaque morphology.

The majority of layered compounds occurring in the mineral form have neutral structure or constitute cationic exchangers; e.g., clay minerals belonging to the 2:1 group. However, layered minerals with anionic exchange properties are rare. Examples of such minerals are hydrotalcite-like compounds, also known as layered double hydroxides (LDHs).

The LDH structure resembles the structure of the mineral Brucite, in which trivalent cations can isomorphically substitute the $\mathrm{Mg}^{2+}$ cations, to generate a positively charged residue. The presence of anions in the LDH interlayer space compensates for this charge and renders these compounds their characteristic anionic exchange capacity.

The formula $\left[\mathrm{M}^{2+}{ }_{1-x} \mathrm{M}^{3+}{ }_{\mathrm{x}}(\mathrm{OH})_{2}\right]^{\mathrm{x+}} \cdot \mathrm{A}^{\mathrm{m}-}{ }_{\mathrm{x} / \mathrm{m}} \cdot \mathrm{nH}_{2} \mathrm{O}$ represents the LDH composition, where $\mathrm{M}^{2+}$ refers to a divalent metallic cation (e.g., $\mathrm{Mg}^{2+}, \mathrm{Zn}^{2+}$, etc.), $\mathrm{M}^{3+}$ corresponds to a trivalent metallic cation (e.g., $\mathrm{Al}^{3+}, \mathrm{Fe}^{3+}$, etc.), and $\mathrm{A}^{m-}$ represents an intercalated hydrated anion with charge $\mathrm{m}^{-}$(e.g., $\mathrm{NO}_{3}{ }^{-}$, $\mathrm{CO}_{3}{ }^{2-}$, etc.). Although $\mathrm{LDH}$ are rare in nature, synthesizing these compounds in the laboratory is easy and relatively inexpensive [38-40].

To be part of the LDH structure, the metallic cations $\mathrm{M}^{2+}$ and $\mathrm{M}^{3+}$ must remain in the center of a hydroxyl-coordinated octahedron, which implies in a limited range of ionic radii. In general, the molar ratio between the di- and trivalent metallic cations in the $\mathrm{LDH}\left(\mathrm{M}^{2+} / \mathrm{M}^{3+}\right)$ can vary from 1 to 8 , which corresponds to $0.5>x>0.11$ in the general $\mathrm{LDH}$ formula. Because each trivalent cation accounts for the excess positive charge in the layers, the $x$ value determines the LDH charge density.

Higher charge density in the layer increases the amount of intercalated anions for each divalent cation, an equivalent amount of anions should intercalate between the LDH layers. Hence, increased $\mathrm{M}^{2+} / \mathrm{M}^{3+}$ molar ratio lowers the charge density and the number of intercalated anions. Consequently, the anions become sufficiently separated, which minimizes interaction between the pillared layers and facilitates delamination and exfoliation. Intercalated anions can be organic or polymeric, for example, which aids tailoring of the LDH properties to the desired application. When a low proportion of organic species intercalates between the layers, neutral organic species can occupy the spaces available between the organic anions, to cause a phenomenon called adsolubilization.

Figure 2 shows a schematic representation of an LDH structure of the 3R polytype (three layers along the basal axis) according to the nomenclature of Ramsdell.

Some literature reports have mentioned that $\mathrm{M}^{4+}$ cations can also substitute $\mathrm{M}^{2+}$ metals in LDHs, but the literature lacks unequivocal confirmation of these structures.

A distinct example of $\mathrm{LDH}$ is the structure of Gibbsite $\left(\mathrm{Al}(\mathrm{OH})_{3}\right)$. This compound reacts with excess lithium salts to form compounds similar to $\mathrm{LDH}$ of the type $\mathrm{Li}_{0.5} \mathrm{Al}(\mathrm{OH})_{3}(\mathrm{~A})_{0.5} \cdot \mathrm{yH}_{2} \mathrm{O}$ or $\left[\mathrm{LiAl}_{2}(\mathrm{OH})_{6}\right] \mathrm{A} \cdot \mathrm{zH}_{2} \mathrm{O}\left(\mathrm{A}=\mathrm{Cl}^{-}, \mathrm{Br}^{-}, \mathrm{NO}_{3}{ }^{-}\right.$, etc. $)$[41]. These compounds are impossible to be synthesized by the regular precipitation route. Indeed, only the reaction of Gibbsite with lithium salts, either in solution or after mechanochemical reaction, yields these compounds. The lithium cations most likely occupy an octahedral site of the Gibbsite structure (Gibbsite is a di-octahedral structure where one octahedral site of the layers is empty), and the hydrated anion intercalates in the interlayer space (Figure 3). Besides Gibbsite, the same type of reaction can also occur for a mixture of Nordstrandite and Bayerite, which bear similar structures [42]. 


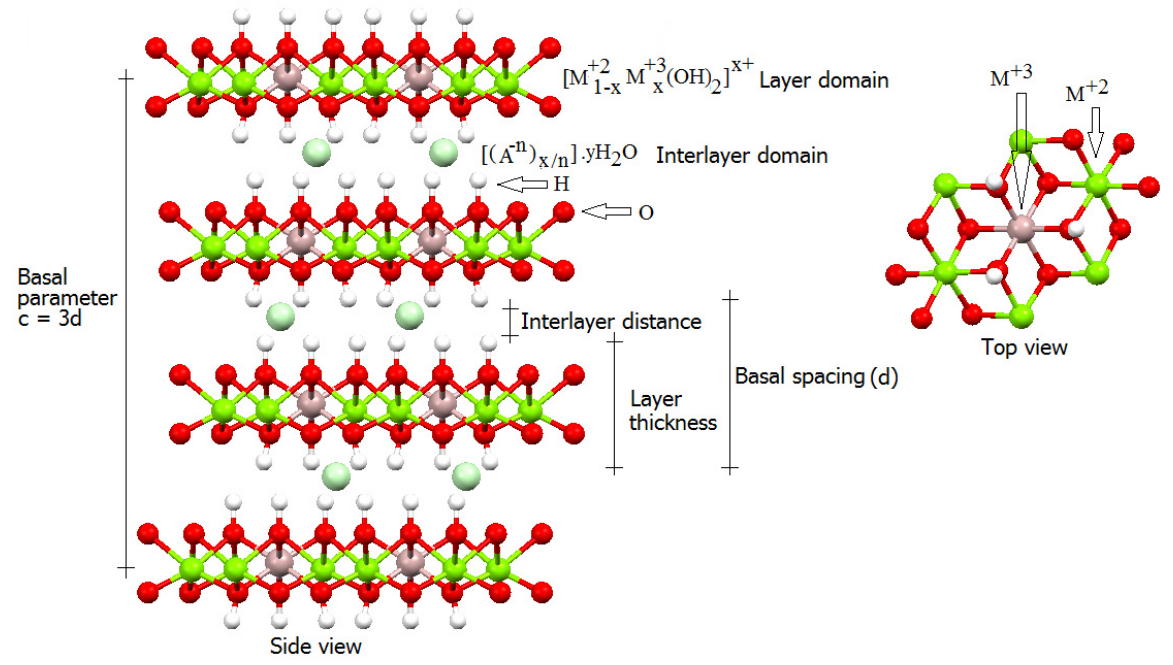

Figure 2. Schematic representation of a generic 3R Layered Double Hydroxide (LDH) structure [36,37].

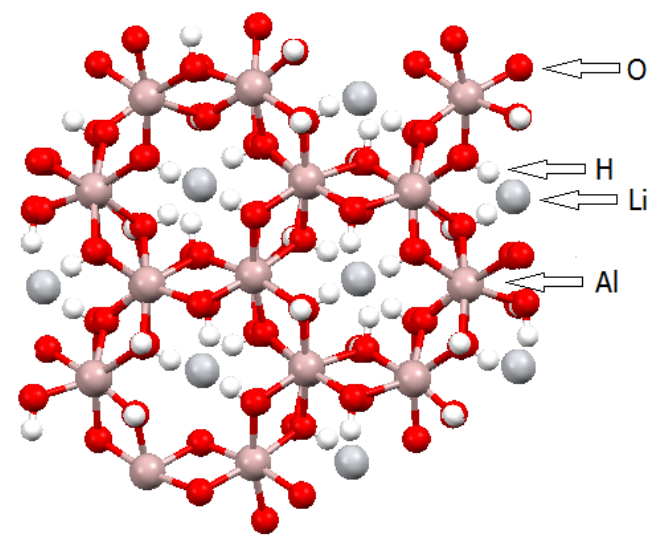

Figure 3. Top view of a single $\left[\mathrm{LiAl}_{2}(\mathrm{OH})_{6}\right] \mathrm{A} \cdot \mathrm{zH}_{2} \mathrm{O}$ layer $\left(\mathrm{A}=\mathrm{Cl}^{-}, \mathrm{Br}^{-}, \mathrm{NO}_{3}{ }^{-}\right.$, etc. $)[36,37]$.

Specific literature review papers exist for the majority of these layered compounds, but a class of layered materials with anionic exchange capacity, denominated layered hydroxide salts (LHSs) and which are rare as mineral, will also be the focus of the present review article.

LHSs are compounds that resemble LDHs, but another mechanism rather than $\mathrm{M}^{2+}$ substitution with $\mathrm{M}^{3+}$ generates the excess positive charge in its layers. The general formulation of LHSs is $\mathrm{M}^{2+}(\mathrm{OH})_{2-x}\left(\mathrm{~A}^{n-}\right)_{\mathrm{x} / \mathrm{n}} \cdot \mathrm{yH}_{2} \mathrm{O}$, where $\mathrm{M}^{2+}$ is a metallic cation (e.g., $\mathrm{Ni}^{2+} \mathrm{Zn}^{2+}, \mathrm{Ca}^{2+}, \mathrm{Cd}^{2+}, \mathrm{Co}^{2+}$, or $\left.\mathrm{Cu}^{2+}\right)$, and $\mathrm{A}$ is a counter anion with charge $\mathrm{n}^{-}$. (Ex.: $\mathrm{NO}_{3}{ }^{-}, \mathrm{SO}_{4}{ }^{2-}, \mathrm{CH}_{3} \mathrm{COO}^{-}$, etc. $\left.[43,44]\right)$.

The cationic layers in the LHS and the LDH structures have distinct generation mechanism. In LHSs, other anions occupy a fraction of the hydroxide sites, as in the case of $\mathrm{Cu}_{2}(\mathrm{OH})_{3} \mathrm{NO}_{3}$. Two different polymorphs exist in this phase. One polymorph is orthorhombic, as reported for the structure of Gerhardtite and other synthetic monoclinic compounds. In the orthorhombic structure of $\mathrm{Cu}_{2}(\mathrm{OH})_{3} \mathrm{NO}_{3}$, nitrate anions substitute one fourth of the hydroxide anions and coordinate with three different $\mathrm{Cu}^{2+}$ cations, to occupy octahedral sites (Figure 4A). Although nitrate anions are grafted to the layers, they can be replaced by means of anion exchange reactions. In the case of the second polymorph, one fourth of the $\mathrm{Zn}^{2+}$ ions present in the octahedral sites are removed from the structure, and two tetrahedral sites are generated in the upper and lower octahedral empty site. The anions are grafted directly to the tetrahedral $\mathrm{Zn}^{+2}$ sites, as observed for the mineral Simonkolleite $\left(\mathrm{Zn}_{5}(\mathrm{OH})_{8} \mathrm{Cl}_{2} \cdot 2 \mathrm{H}_{2} \mathrm{O}\right)$ (Figure $\left.4 \mathrm{~B}\right)$. A third polymorph in which a structure similar to Simonkolleite contains water molecules directly bound to the tetrahedral $\mathrm{Zn}^{2+}$ sites is also possible, but it requires 
the presence of a counter anion in the second coordination sphere, to neutralize the positive charges of the layers (e.g., $\left.\mathrm{Zn}_{5}(\mathrm{OH})_{8}\left(\mathrm{NO}_{3}\right)_{2} \cdot 2 \mathrm{H}_{2} \mathrm{O}\right)$ (Figure $4 \mathrm{C}$ ).
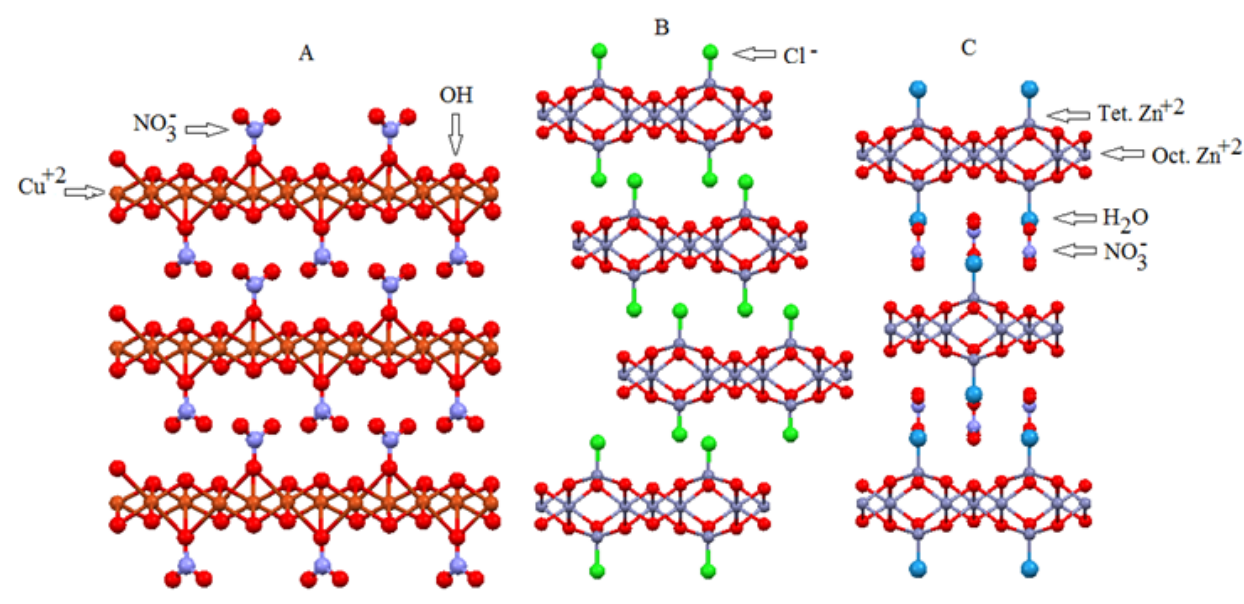

Figure 4. Side view of the structures of: (A) Copper hydroxite nitrate; (B) Zinc hydroxide chloride; (C) Zinc hydroxide nitrate. Hydrogen atoms were removed from the structure to facilitate visualization [36,37].

The structure of the aforementioned zinc hydroxide nitrate $\mathrm{Zn}_{5}(\mathrm{OH})_{8}\left(\mathrm{NO}_{3}\right)_{2} \cdot 2 \mathrm{H}_{2} \mathrm{O}$ can be considered a structural variation of the $\mathrm{Zn}(\mathrm{OH})_{2}$ structure, where one fourth of the octahedral $\mathrm{Zn}^{2+}$ cations are removed from the layer. Every octahedral site occupied by a $\mathrm{Zn}^{2+}$ cation shares edges with two empty and four occupied octahedra, producing a layer with a residual negative charge $\left(\left[\mathrm{Zn}_{3}(\mathrm{OH})_{8}\right]^{2-}\right)$. To compensate for the deficit in positive charge, tetrahedral $\mathrm{Zn}^{2+}$ cations accommodate below and above the empty octahedra of the layer. In this way, three corners of the tetrahedra coordinate with oxygen atoms of the layer, whereas the fourth position coordinates with a water molecule. In this configuration, the layer is positively charged $\left[\mathrm{Zn}_{3 \text { (oct.) }}(\mathrm{OH})_{8} \mathrm{Zn}_{2 \text { (tet.) }}\left(\mathrm{H}_{2} \mathrm{O}\right)_{2}\right]^{2+}$, where "oct." and "tet." represent the $\mathrm{Zn}^{2+}$ cations located in octahedral and tetrahedral sites, respectively. To neutralize the residual positive charge of the layer, anions intercalate between the layers. Nitrate anions intercalate between the layers in the case discussed here.

Natural minerals contain more than one metal, which has led to identification of several layered hydroxide slats containing two different divalent metals. The resulting compounds are denominated double hydroxide salts (DHSs). They have the generic formula $\mathrm{M}^{\mathrm{a}}{ }_{1-x} \mathrm{M}^{\mathrm{b}}{ }_{\mathrm{x}}(\mathrm{OH})_{2-x}\left(\mathrm{~A}^{n-}\right)_{\mathrm{x} / \mathrm{n}} \cdot \mathrm{yH}_{2} \mathrm{O}$, where $M^{a}$ and $M^{b}$ are two different divalent cations, and $A$ is the counter anion with charge $n^{-}$. Aurichalcite $\left((\mathrm{Zn}, \mathrm{Cu})_{5}\left(\mathrm{CO}_{3}\right)_{2}(\mathrm{OH})_{6}\right)$, Haydeeite $\left(\mathrm{Cu}_{3} \mathrm{Mg}(\mathrm{OH})_{6} \mathrm{Cl}_{2}\right)$ and Kapelassite $\left(\mathrm{Cu}_{3} \mathrm{Zn}(\mathrm{OH})_{6} \mathrm{Cl}_{2}\right)$, among others [45], are examples of these structures.

Less frequently, layered hydroxide salts with three different metals have been reported; e.g., Loseyite $(\mathrm{Mn}, \mathrm{Zn}, \mathrm{Mg})_{4} \mathrm{Zn}_{3}\left(\mathrm{CO}_{3}\right)_{2}(\mathrm{OH})_{10}$ or Sclarite $(\mathrm{Mn}, \mathrm{Zn}, \mathrm{Mg})_{4} \mathrm{Zn}_{3}\left(\mathrm{CO}_{3}\right)_{2}(\mathrm{OH})_{10}[46,47]$.

\section{LDH and LHS as Support for Metalloporphyrin Immobilization}

\subsection{Layered Double Hydroxides (LDHs)}

Natural or synthetic layered compounds can immobilize a great variety of charged species, leading to several applications. These compounds are commonly used as ion exchangers [48], but they can also be employed in catalysis [49] and in the biological and medical fields [50], not to mention their use as flame retardants [51].

MP immobilization or even intercalation into LDHs has been known for over 20 years, as attested by the review of Bedioui published in 1995 [11]. In 2012, Demel and Lang published a short review dedicated to MP immobilization and application of the resulting material in catalysis [30]. 
To discuss MP immobilization on LDHs and the catalytic activity of the final materials, it is worth mentioning the work of Wypych et al. [52] published in 2003, which reported immobilization of an anionic iron (III) porphyrin (FeP) through LDH exfoliation processes. Based on the XRD data, the FeP was probably located on the surface of the exfoliated and restacked layered crystals. Later, the first investigation into the catalytic activity of FePs immobilized on exfoliated LDHs as heterogeneous catalysts was reported [53]. These materials catalyzed hydroxylation reactions selectively and efficiently. Their reuse afforded higher yields than the parent fresh catalyst probably because the LDH crystals re-accommodated and exposed the active FeP catalytic sites [53].

In the last years, different strategies have helped to create new catalysts involving MP immobilized on different LDHs. In 2013, He and co-workers developed a new catalyst by encapsulating the MnP [Mn(TPP)OAc] into $\mathrm{Zn} / \mathrm{Al}-\mathrm{LDH}$ (an LDH prepared with $\mathrm{Zn}^{2+}$ and $\mathrm{Al}^{3+}$ ) intercalated with dodecyl sulfonate. These authors designed and prepared this solid aiming to obtain a structure that resembled the structure expected for a bilayer of naturally occurring phospholipids [54]. The catalytic activity of the resulting catalyst in the oxidation of a series of alkenes including cyclohexene, heptylene, phenylethylene, 3-methyl-3-buten-1-ol, ethyl cinnamate, and chalcone afforded superior results as compared to the parent compound in solution (homogeneous reactions), which indicated that this material had promising activity for alkene oxidation. These immobilization strategies opened the possibility to immobilize neutral as well as anionic MPs between LDH layers.

Recently, Jaina et al. [55] published a work where they described the synthesis of a magnetically separable LDH named $\mathrm{Mg} / \mathrm{Al}-\mathrm{LDH} @ \mathrm{Fe}_{3} \mathrm{O}_{4}$. The authors used this solid to immobilize a cobalt phthalocyanine catalyst. The resulting material effectively catalyzed the oxidation of mercaptans by molecular oxygen in aqueous medium. An external magnetic field promoted easy recovery of this catalyst from the reaction medium [55]. Facile catalyst recovery and reuse allied with the use of molecular oxygen and water as solvent qualified this solid as an interesting catalyst for green processes.

Nakagaki and co-workers [56] recently reported immobilization/intercalation of an FeP into exfoliated macroporous LDH. Oxidation of two model substrates, (Z)-cyclooctene and cyclohexane, by $\mathrm{PhIO}$ in the presence of this material proved that the immobilized FeP not only was a potential catalyst for heterogeneous processes but also had promising technological applications.

A second-generation $\mathrm{MnP}$ intercalated into the interlayer space of different LDHs containing $\mathrm{Mg}^{2+}$ or $\mathrm{Ni}^{2+}$ and $\mathrm{Al}^{3+}$ by the exfoliation/restacking approach, using organic groups as building blocks, efficiently and selectively catalyzed cyclohexene epoxidation by molecular oxygen in the presence of isobutylaldehyde as co-reductant [57]. The reused catalyst afforded product yields that resembled the yield achieved with the fresh catalyst and that were higher than the yield obtained during homogeneous catalysis (MP catalyst in solution).

More complex structures like iron or manganese glycol metalloporphyrin immobilized on LDHs have also been investigated as catalysts for hydroxylation and epoxidation reactions by iodosylbenzene. The immobilized MPs provided good catalytic yield in the epoxidation reaction, and they selectively catalyzed cyclohexane oxidation. The solids were used in at least three catalytic cycles in the case of epoxidation reactions. The reusability and stability of the MP-LDH catalysts pointed to a promising and economically viable process [4].

The use of LDHs as support for MPs has applications in other fields. Bearing in mind that free-base porphyrins can act as photosensitizers in allylic oxidation, researchers have investigated the photocatalytic activity of the $[\mathrm{Fe}(\mathrm{TPFPP}) \mathrm{Cl}] / \mathrm{Mg} / \mathrm{Al}-\mathrm{LDH}$ system for aerobic alkene epoxidation under visible-light irradiation. The catalyst was selective for 1,2-epoxycyclohexane during photocatalytic aerobic cyclohexene epoxidation. The authors concluded that [Fe(TPFPP)Cl]/Mg/Al-LDH was an effective photocatalyst for the oxidation of various alkenes [58].

Natural protein immobilization is another research field that uses the versatile LDHs associated with tetrapyrrolic macrocycles. Different techniques such as XRD (powder), UVVIS, and fluorescence spectroscopies have aided understanding of the role that ionic liquid plays in the interaction between $\mathrm{LDH}$ and hemoglobin $(\mathrm{Hb})$ upon $\mathrm{Hb}$ immobilization on $\mathrm{Zn}_{2} \mathrm{Al}-\mathrm{LDH}$ modified with 
hydroxyl-functionalized ionic liquid by the co-precipitation or the adsorption method. Investigation of the electrocatalytic activity of the immobilized $\mathrm{Hb}$ by cyclic voltammetry showed that co-precipitation was apparently more effective for enzyme immobilization, and that the resulting materials constituted electrochemical biosensors [59].

In order to facilitate the lecture, Table 1 summarizes the main MP immobilized on LDH and discussed above.

Table 1. Summary of the main MP immobilized in LDH in Section 2.1.

\begin{tabular}{|c|c|c|c|}
\hline MP & LDH & Use & Reference \\
\hline $\begin{array}{l}\text { Fe or Mn glycol } \\
\text { metalloporphyrin }\end{array}$ & $\mathrm{Mg} / \mathrm{Al}-\mathrm{LDH}$ (nitrate anions) & $\begin{array}{l}\text { Oxidation of cyclooctene } \\
\text { and cyclohexane }\end{array}$ & [4] \\
\hline $\begin{array}{l}{[\mathrm{Fe}(\mathrm{TDFSPP})] \text { and }} \\
{[\mathrm{Fe}(\mathrm{TCFSPP})]}\end{array}$ & $\mathrm{Mg} / \mathrm{Al}-\mathrm{LDH}$ (glycinate anions) & $\begin{array}{l}\text { Oxidation of cyclooctene } \\
\text { and cyclohexane }\end{array}$ & [53] \\
\hline $\mathrm{Mn}(\mathrm{TPP}) \mathrm{OAc}$ & $\begin{array}{l}\mathrm{Zn} / \mathrm{Al}-\mathrm{LDH} \text { (dodecyl } \\
\text { sulfonate anions) }\end{array}$ & Epoxidation of alkenes & {$[54]$} \\
\hline CoPcS (phthalocyanine) & $\mathrm{Mg} / \mathrm{Al}-\mathrm{LDH} @ \mathrm{Fe}_{3} \mathrm{O}_{4}$ (magnetic) & Oxidation of mercaptans & [55] \\
\hline [Fe(TDCSPP)] & Mg/Al-LDH (macroporous) & $\begin{array}{l}\text { Oxidation of cyclooctene } \\
\text { and cyclohexane }\end{array}$ & [56] \\
\hline MnTSPP & $\begin{array}{l}\text { Mg or Ni/Al-LDH } \\
\text { (intercalated porphyrin) }\end{array}$ & Epoxidation of cyclohexene & [57] \\
\hline [Fe(TPFPP)Cl] & $\mathrm{Mg} / \mathrm{Al}-\mathrm{LDH}$ (nitrate anions) & Epoxidation of cyclohexene & [58] \\
\hline
\end{tabular}

\subsubsection{Other Macrocycles Immobilized in LDH}

Macrocyclic compounds are among the species that can be immobilized on LDH supports. In recent decades, the number of investigations into these synthetic compounds has increased and improved our understanding of their coordination chemistry. Because of their relative stiffness and variety, these compounds can form complexes with different metals, which leads to a huge variety of applications that range from biological models to sophisticated catalytic applications.

Various macrocyclic complexes can interact with LDHs, especially phthalocyanines and porphyrins. More recently, interaction of anionic crown ethers and calixarene compounds (Figure 5) with LDHs has been described [60-71].

Pinnavaia et al. [60] authored the first paper on a macrocyclic complex interlayered in an LDH and reported on a promising catalyst to oxidize 2,6-di-tert-butylphenol: a catalyst based on heterogenization of a tetra anionic Co(II) tetrasulfophthalocyanine [CoPcTs] ${ }^{4-}$ (Figure 5a) intercalated into a $\mathrm{Mg} / \mathrm{Al} \mathrm{LDH}$ at $\mathrm{M}^{2+} / \mathrm{M}^{3+}$ molar ratio of 2:1 and 4:1. The turnover frequency of the immobilized compounds was twice as great as the turnover frequency of the complex [CoPcTs] in solution, which indicated that the substrate had easier access to the active center. The authors also concluded that heterogenization inhibited Co(II) phthalocyanine dimerization [60]. Several other authors have evaluated phthalocyanines as catalysts for countless catalytic reactions such as oxidation of 1-decanethiol [60], 2,6-di-tert-butylphenol (to the corresponding diphenoquine) [61], and mercaptan [62] as well as photocatalytic methylene blue decoloration [63].

Carraro et al. developed various solids based on either anionic or cationic copper(II) phthalocyanine intercalated into clay minerals and LDH [64]. Basal distance results obtained by X-ray diffraction of the resulting LDH materials evidenced that the phthalocyanine intercalated between the LDH layers. The prepared solid was based on a copper(II) phthalocyaninetetrasulfonic acid tetrasodium salt (CuPcTs) intercalated into LDH, where the immobilized metallophthalocyanine was perpendicular to the LDH layers. After publication of this paper, many other studies involving different metallophthalocyanines intercalated into LDHs were prepared to ascertain their mode of 
interaction with the LDH. Here, the studies reported by Ukrainczyk and co-workers are worthy of mention $[65,66]$.

Macrocycles derived from the crown ether family are also interesting to intercalate into LDHs. $\mathrm{Ma}$ et al. intercalated a carboxyethyl-substituted azacrown ether derivative (CSAE) (Figure 5b) into a Mg/Al-LDH by exchanging the crown ether with the intercalated nitrate anions. These authors aimed to understand how the CSAE accommodated between the LDH layers, prepared under different conditions [67]. Although the LDH contained co-intercalated carbonate anions, it was possible to predict the arrangement modes of the intercalated species. Because the azacrown ether molecules were flexible, they inclined and the crown could assume distinct orientation modes.

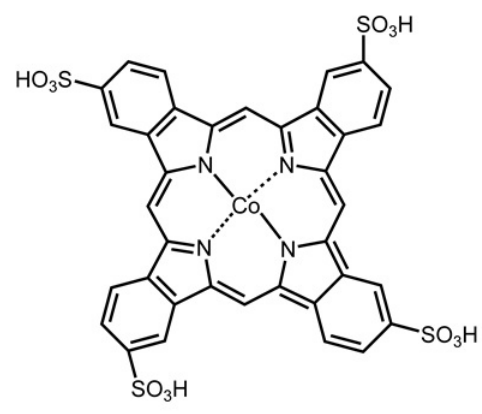

(a)

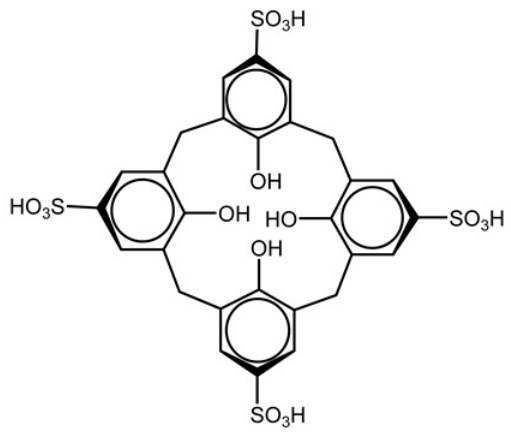

(b)

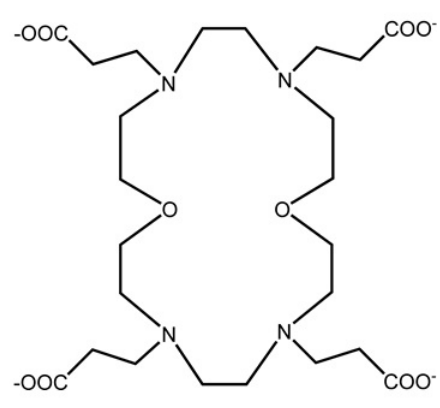

(c)

Figure 5. Structure of: (a) Co(II) tetrasulfophthalocyanine; (b) Carboxyethyl substituted azacrown ether derivative (CSAE); (c) $p$-sulfonated calixarene.

Ma et al. also investigated staging formation after swelling of the intercalated LDH in formamide. The structure was restored in the presence of the macrocyclic tetraazacrown ether carboxylic acid derivative (TECA) [68]. Similarly, a procedure was developed for direct "one-step" intercalation of the macrocyclic tetraazacrown ether carboxylic acid derivative (TECA) into the Mg/Al-LDH interlayer [69]. In both cases [68,69], TECA co-intercalated with nitrate or carbonate anions, depending on the synthesis procedure.

Sasaki and co-workers synthesized $p$-sulfonated calix [4 (CS4) and 6 (CS6)] arene (Figure 5c) intercalated into LDHs and studied the ability of the resulting material to adsorb benzyl alcohol (BA) and $p$-nitrophenol (NP) [70,71]. The authors varied the chemical composition of the LDH support by using different divalent metals $\left(\mathrm{Mg}^{2+}\right.$ and $\left.\mathrm{Zn}^{2+}\right)$ and keeping $\mathrm{Al}^{3+}$ as the trivalent metal; the $\mathrm{M}^{2+} / \mathrm{M}^{3+}$ molar ratio was 3:1. The authors also varied the number of calixarene ring units (four and six phenol units). For CS6 (six phenol rings), there were no differences in the interaction mode of calixarene with the LDH layers; that is, the immobilized compound was perpendicular to the LDH regardless of the presence of $\mathrm{Mg}^{2+}$ or $\mathrm{Zn}^{2+}$. However, for CS4 (four phenol rings), there were two immobilization modes, which depended on the LDH composition. The X-ray diffraction patterns showed that CS4 intercalated vertically and horizontally relative to the Mg/Al-LDH and Zn/Al-LDH layer plane, respectively $\left(\mathrm{d}_{003}=1.33 \mathrm{~nm}\right.$ and $1.61 \mathrm{~nm}$, respectively). The distinct CS4 orientations were due to the different $\mathrm{pH}$ values used during the synthesis $(\mathrm{pH}=10$ and 7 for $\mathrm{Mg} / \mathrm{Al}-\mathrm{LDH}$ and $\mathrm{Zn} / \mathrm{Al}-\mathrm{LDH}$, respectively), which ionized a different number of $\mathrm{OH}$ groups in CS4 ( $\mathrm{p} K_{\mathrm{a} 1}=3.08$ and $\mathrm{pK}_{a 2-4}>11$ ). Different CS4 orientation modes strongly influenced BA and NP adsorption on the surface of LDH crystals. BA adsorption was 2.10 and 0.22 (BA/CS4 molar ratio) for CS4 intercalated into $\mathrm{Zn} / \mathrm{Al}-\mathrm{LDH}$ and $\mathrm{Mg} / \mathrm{Al}-\mathrm{LDH}$, respectively, and NP adsorption was 4.50 and 0.76 (NP/CS4 molar ratio) for CS4 intercalated into $\mathrm{Zn} / \mathrm{Al}-\mathrm{LDH}$ and $\mathrm{Mg} / \mathrm{Al}-\mathrm{LDH}$, respectively. Therefore, CS4 intercalated into $\mathrm{Zn} / \mathrm{Al}-\mathrm{LDH}$ (where CS4 was parallel to the layers) adsorbed larger quantities of BA and NP than CS4 intercalated into Mg/Al-LDH (where CS4 was perpendicular to the layers). 


\subsection{Layered Hydroxide Salts (LHSs)}

Despite reports on the synthesis of some LHSs in the 1970s [72,73], only recently did LHSs as support and LHSs for other applications gain attention [43,74-76]. LHSs can serve as support for anions derived from mono- and dicarboxylic acids [77], sodium dodecyl sulfate [75], different dyes [78], and palladium porphyrins [79]. Some authors investigated LHS surfaces [74] and the use of LHSs as catalyst for esterification of free fatty acids [80].

Our research group first reported on LHSs as supports to immobilize MPs for use in catalyzed heterogeneous oxidation processes in 2010 [34]. In this work, a family of second-generation anionic FePs (Figure 6) were immobilized on the surface of zinc hydroxide nitrate (ZHN) and investigated as oxidation catalysts for heterogeneous cyclooctene, cyclohexane, and $n$-heptane oxidation [34]. Besides the excellent yields that the catalysts provided during cyclooctene and $n$-heptane oxidation, they were surprisingly selective for cyclohexanone instead of the alcohol product. During cyclohexane oxidation, the catalyst FeTDCSPP-ZHN (FeDC-ZHN) afforded up to $70 \%$ cyclohexanone and only $2 \%$ cyclohexanol after one hour of reaction [34], this behavior contrasted with the classic mechanism of oxidation catalyzed by FePs in solution (homogeneous catalysis), which are frequently selective for cyclohexanol [81-84] and act via the catalytic species ferryl porphyrin $\pi$-cation radical $\mathrm{Fe}^{\mathrm{IV}}(\mathrm{O}) \mathrm{P}^{\bullet+}[5,10,34,81,82]$. In FeDC-ZHN, the FeP probably interacted with the ZHN surface, to create an ambience that favored the radical oxidation mechanism instead of the classic oxidation mechanism [17]. In this same work by our group [34], the FeP-ZHN catalysts were selective for the alcohols instead of the ketone during $n$-heptane oxidation. These results strongly suggested that the structure of the substrate and the $\mathrm{FeP}$ immobilization mode tuned the catalytic results. The structure of $n$-heptane is linear, whereas the cyclic structure of cyclohexane can acquire the "boat" and "chair" configurations [19]. This culminated in distinct selectivity results for the two substrates even though the catalyst was the same.

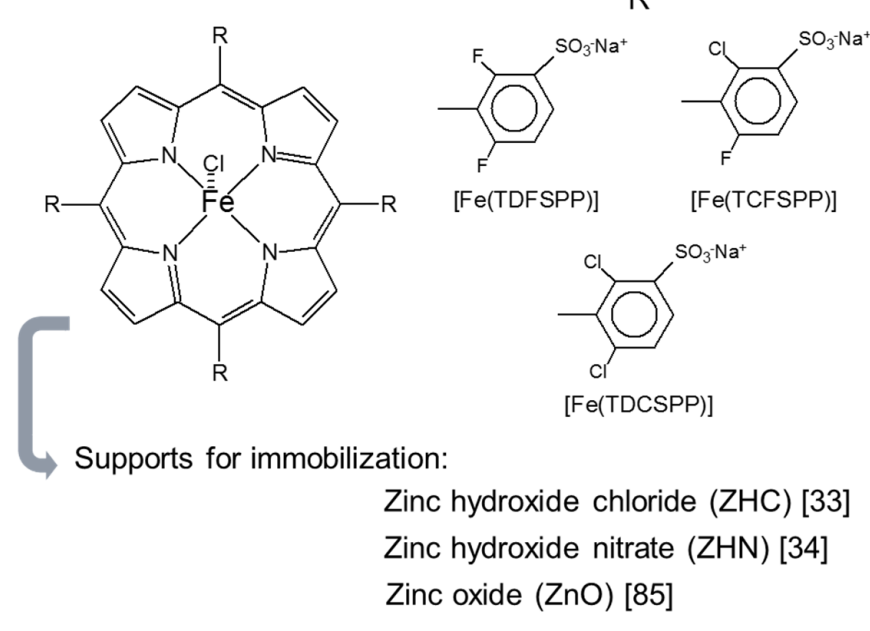

Figure 6. Structure of the anionic iron(III) porphyrins (FeP) employed in references $[33,34,85]$. $\left[\mathrm{Fe}(\mathrm{TDFSPP}) \mathrm{Na}_{4}\right] \mathrm{Cl}=$ [tetrasodium-5,10,15,20-tetrakis(2,6-difluoro-3-sulfonatophenyl)porphyrinate iron(III)] chloride; [Fe(TCFSPP) $\left.\mathrm{Na}_{4}\right] \mathrm{Cl}=$ [tetrasodium-5,10,15,20-tetrakis (2-chloro-6-fluoro-3sulfonatophenyl)porphyrinate iron(III)] chloride, and [Fe(TDCSPP) $\left.\mathrm{Na}_{4}\right] \mathrm{Cl}=[$ tetrasodium-5,10,15,20tetrakis(2,6-dichloro-3-sulfonatophenyl) porphyrinate iron(III)] chloride.

The same family of FePs (Figure 6) was also immobilized on layered zinc hydroxide chloride (ZHC) [33]. Replacing the exchangeable nitrate ion with the chloride ion grafted in the layer composition elicited a different catalytic activity. The FeP immobilization degree in LHSs changed (immobilization degree is the percentage of FeP immobilized on the solid support relative to the mass of FeP used during the immobilization procedure). For the same immobilization reaction conditions, 
the immobilization degree of the three FePs on ZHN was near 100\% [34], whereas the immobilization degree was approximately 30\% [33] in the ZHC support. This difference was attributed to non-effective coordination of nitrate to the ZHN layers [43]. The anionic FeP substituted the free nitrate ion located between the layers and on the ZHN solid surface [34,79]. In the case of the ZHC support, the chloride ions were directly coordinated to the layers [43] and could not be exchanged with the anionic complex. This left only the positive charges on the crystal edges to interact with the FePs [33]. FeP immobilization on different LHS sites directly influenced the oxidation catalysis results. Catalysts immobilized on ZHN and ZHC were selective for cyclohexanone and cyclohexanol during cyclohexane oxidation, respectively [33], which meant that the reaction followed the classic route expected for FePs in solution in the latter case $[10,17,82]$. Indeed, FeTDCSPP-ZHC (FeDC-ZHC) afforded 23\% cyclohexanol and 2\% cyclohexanone yields [33] vs. $70 \%$ cyclohexanone and $2 \%$ cyclohexanol achieved in the presence of FeTDCSPP-ZHN in the same reaction conditions. The reaction conducted in the presence of the FeP immobilized on $\mathrm{ZHN}$ followed a radical mechanism, and the total product yield (ketone + alcohol) was higher than the total product yield obtained in the case of the FeP immobilized on ZHC. These examples attested that MPs are versatile catalysts and point to the importance of the support when preparing a solid catalyst for heterogeneous processes.

Demel and Lang published a short review about layered hydroxide-porphyrin hybrid materials [30] where they summarized findings for some systems involving LDHs and LHSs containing intercalated anionic MPs or phthalocyanines. The authors discussed some aspects like synthetic strategies for the intercalated compounds, structural aspects based on characterization techniques, photo functional applications, and use in catalysis. To the best of our knowledge, there has been no other work on MPs immobilized on LHSs as catalysts for oxidation reactions since this review. However, this is a very interesting research field: many LHSs, with diverse metallic ions (e.g., $\mathrm{Cu}^{2+}$, $\mathrm{Co}^{2+}$, and $\mathrm{Ni}^{2+}$ ) and interlayer anions (e.g., $\mathrm{Cl}^{-}, \mathrm{CO}_{3}{ }^{2-}, \mathrm{SO}_{4}{ }^{2-}$, and organic anions with different chain lengths), can serve as support for MP immobilization. Some of the resulting catalysts could even elicit unusual selectivity for cyclohexane oxidation, as observed when ZHN was the support [34].

Despite the rare use of LHSs as support for MPs and their potential application as oxidation catalysts, an interesting property of LHSs has been investigated for MP immobilization: the in situ generation of oxides from the layered structure [85-89].

\subsubsection{Oxides Derived from LHSs}

LHSs can be decomposed into the respective oxide by thermal treatment. For example, treatment of zinc hydroxide carbonate at $300{ }^{\circ} \mathrm{C}$ [86], zinc hydroxide nitrate at $400{ }^{\circ} \mathrm{C}$ [87], and zinc hydroxide sulfate at $900{ }^{\circ} \mathrm{C}[88]$ generates the respective $\mathrm{ZnO}$.

Hydrothermal treatment can also transform LHS into the corresponding oxide [85,89] by keeping the LHS suspension in water in reflux at $100{ }^{\circ} \mathrm{C}$ [85] or in an autoclave at $140{ }^{\circ} \mathrm{C}$ [89]. Another way to obtain the respective oxide is to increase the $\mathrm{pH}$ during the LHS synthesis the LHS does not separate from the reaction mixture, and the oxide emerges at $\mathrm{pH}$ higher than 8 [43,79]. Musić et al. employed $8 \mathrm{~mol} \cdot \mathrm{L}^{-1} \mathrm{NaOH}$ solution to obtain $\mathrm{ZnO}$ directly from a $1 \mathrm{~mol} \cdot \mathrm{L}^{-1} \mathrm{Zn}\left(\mathrm{NO}_{3}\right)_{2}$ solution [90]. The method used to obtain the oxide depends on the research objective.

The oxide obtained from LHSs has a high degree of purity, and its crystals retain the morphology of the initial LHS (topotactic growth) $[43,88]$. Another advantage is that the methods that produce these oxides are easy to accomplish.

In 2011, Huang and co-workers published a work where they immobilized a cobalt tetra(4-hydroxyl)phenylporphyrin [Co(THPP)] on $\mathrm{ZnO}$ obtained from zinc hydroxide sulfate [24]. To synthesize the support, the researchers used a zinc sulfate heptahydrate solution, which provided the metal and $\mathrm{NaOH}$ (as the source of hydroxide ions). The authors then immobilized [Co(THPP)] on the obtained solid, and the final solid was dried at $160{ }^{\circ} \mathrm{C}$ for $5 \mathrm{~h}$ [24]. The solid material selectively catalyzed toluene oxidation by $\mathrm{O}_{2}$ to benzaldehyde and benzylalcohol. The $[\mathrm{Co}(\mathrm{THPP})] / \mathrm{ZnO}$ solid was a better catalyst than $[\mathrm{Co}(\mathrm{THPP})]$ in homogeneous solution due to a cooperative association 
between the support and the MP [24]. As verified in the case of FePs immobilized on ZHN [34], the support was not innocent or inert during the catalytic reactions.

In 2013, our research group used $\mathrm{ZnO}$ as support to immobilize the same FeP family that our group had immobilized on ZHN [34] and ZHC [33]. ZHN hydrothermal decomposition furnished $\mathrm{ZnO}$ [85]. Addition of each FeP (Figure 6) was to a $\mathrm{ZHN}$ suspension in water, and $5 \mathrm{~h}$ under stirring and reflux generated $\mathrm{ZnO}$ containing the immobilized complex [85]. Changing the LHS to the oxide caused collapse of the layered structure and loss of the tetrahedral zinc sites, to give a non-corrugated $\mathrm{ZnO}$ surface. Anionic MP immobilization on the $\mathrm{ZnO}$ surface was possible because residual positive charges existed on the oxide surface in the $\mathrm{pH}$ employed during the immobilization process [43]. Loss of the ZHN corrugated surface re-established the usual FeP behavior for the FePs immobilized on ZnO; that is, selectivity for cyclohexanol during cyclohexane oxidation [85]. In the case of FeTDCPP-ZnO, the cyclohexanol and cyclohexanone yields were $22 \%$ and $3 \%$, respectively, which resembled the results achieved for FeTDCSPP-ZHC (cyclohexanol and cyclohexanone yields of $23 \%$ and $2 \%$, respectively) but contrasted with the results obtained for FeTDCSPP-ZHN (cyclohexanol and cyclohexanone yields of $2 \%$ and $70 \%$, respectively). These data corroborated the fact that the environment created around the FeP in $\mathrm{ZHN}$ was unique and led to the radical route during cyclohexane oxidation. Decomposition of the corrugated structure made the reaction mechanism return to the classic route $[17,34,85]$.

In 2015, Huang and co-workers immobilized an iron(III)) tetrakis(pentafluorophenyl)porphyrin [Fe(TPFPP)] onto $\mathrm{ZnO}$ and studied the catalytic activity of this solid during cyclohexane oxidation [91]. These authors used the same procedure employed in our work of 2011 [24] to obtain $\mathrm{ZnO}$ and to immobilize [Fe(TPFPP)] on the support. The authors detected a blue shift in the Soret band (from $416 \mathrm{~nm}$ to $405 \mathrm{~nm}$ ) upon [Fe(TPFPP)] immobilization on $\mathrm{ZnO}$. This behavior was attributed to face-to-face/parallel immobilization of the $\mathrm{FeP}$ on the $\mathrm{ZnO}$ surface, which led the negative fluorine atoms and the positive $\mathrm{ZnO}$ surface to interact and give a more planar [Fe(TPFPP)] structure. The authors used [Fe(TFPP)]-ZnO to catalyze cyclohexane oxidation by $\mathrm{O}_{2}$ in an autoclave at $150{ }^{\circ} \mathrm{C}$; they did not use solvent or co-catalysts [91]. At $150^{\circ} \mathrm{C}, 1.0 \mathrm{mg}$ of [Fe(TPFPP)] in $\mathrm{ZnO}$ gave product yield of $22.5 \%$, which was higher than the yield obtained with $1.0 \mathrm{mg}$ of non-immobilized [Fe(TPFPP)]: $15.0 \%$. According to the authors, the higher reaction yield resulted from the cooperative effect between the $\mathrm{FeP}$ and the support, probably $\mathrm{FeP}$ coordination to $\mathrm{ZnO}$, as explained in the former work by our group [24]. Huang and co-workers [91] also proposed that a peroxide species arose during catalysis and underwent rapid conversion to the desired products.

Still in 2015, Xie et al. immobilized a [trans-CoD(p-Cl)PP] on various supports [25] such as boehmite, $\mathrm{ZrO}_{2}, \mathrm{MCM}, \mathrm{ZnO}$, and others. These authors obtained $\mathrm{ZnO}$ from a zinc sulfate heptahydrate aqueous solution and $\mathrm{NH}_{4} \mathrm{OH}$ (as the hydroxide source). The authors tested cyclohexane oxidation by $\mathrm{O}_{2}$ in an autoclave, without solvent or co-catalyst, in a procedure resembling the procedure described by Huang et al. [91]. The researchers investigated how pressure, temperature, and time affected the catalytic reaction [25]. They reported that the best support was $\mathrm{ZnO}$, which afforded good substrate conversion, high turnover number, and selectivity.

Finally, $\mathrm{Li}$ and co-workers [92] used a $\mathrm{Zn}\left(\mathrm{CH}_{3} \mathrm{COO}\right)_{2}$ aqueous solution added with $\mathrm{NaOH}$ aqueous solution, treated in an autoclave at $120^{\circ} \mathrm{C}$, to generate $\mathrm{ZnO}$ microrods. The authors immobilized a hetero aggregate of porphyrins (tetrakis(4-trimethylaminophenyl) porphyrin $\left[\mathrm{H}_{2}(\mathrm{TAPPI})\right]$ and tetrakis(4-sulfonatophenyl) porphyrin cobalt(II) [Co(TPPS)]) on this support and employed it in the photodegradation of the rhodamine $\mathrm{B}$ dye with good results [92]. Therefore, $\mathrm{ZnO}$ obtained from LHSs is a versatile support.

\section{Influence of the LDH Composition on the MnP Immobilization Rates and Catalytic Performance: New Results}

Motivated by the rich chemistry of MP immobilization on layered compounds and its implication for the efficiency and selectivity of the obtained solids, our research group has studied how the LDH composition impacts the immobilization rates and catalytic performance in cyclooctene oxidation of 
[5,10,15,20-tetrakis(2,6-difluoro-3-sulfonatephenyl porphyrinate) manganese(III)] acetate (MnP) (the parent FeP is illustrated in Figure 6).

First, we synthesized different LDH solids by obtaining LDHs from magnesium or zinc salts $\left(\mathrm{M}^{2+}\right)$ and aluminum $\left(\mathrm{M}^{3+}\right)$ at different nominal molar ratios $\left(\mathrm{M}^{2+} / \mathrm{M}^{3+}=2: 1,3: 1\right.$ or 4:1), with different interlayer anions $\left(\mathrm{CO}_{3}{ }^{2-}\right.$ and $\left.\mathrm{NO}_{3}{ }^{-}\right)$. The co-precipitation method with increasing $\mathrm{pH}$ yielded LDHs containing intercalated carbonate or nitrate [93]. Table 2 shows the nomenclature used for the obtained solids.

Table 2. Nomenclature used for the prepared LDH solids with different intercalated anions, basal distance (obtained by XRPD experiments) and calculated "a" parameter.

\begin{tabular}{|c|c|c|c|c|c|c|c|}
\hline $\begin{array}{c}\mathrm{Mg} / \\
\text { Al-Anion }\end{array}$ & $\begin{array}{l}\text { Mg:Al } \\
\text { (Molar } \\
\text { Ratio) }\end{array}$ & $\begin{array}{c}\text { Basal } \\
\text { Distance/(§̊) }\end{array}$ & $\begin{array}{c}\text { "a" } \\
\text { Parameter/(̊̊) c }\end{array}$ & Zn/Al-Anion * & $\begin{array}{c}\text { Zn:Al } \\
\text { (Molar } \\
\text { Ratio) }\end{array}$ & $\begin{array}{c}\text { Basal } \\
\text { Distance/(§̊) }\end{array}$ & $\begin{array}{c}\text { "a" } \\
\text { Parameter/(A) c }\end{array}$ \\
\hline $\mathrm{LDH}^{\mathrm{a}}$ & $2: 1$ & 7.57 & 3.036 & $\mathrm{LDH}_{4}{ }^{\mathrm{a}}$ & $2: 1$ & 7.38 & 3.041 \\
\hline $\mathrm{LDH}^{\mathrm{a}}{ }^{\mathrm{a}}$ & $3: 1$ & 7.60 & 3.037 & $\mathrm{LDH}^{\mathrm{a}}$ & $3: 1$ & 7.22 & 3.052 \\
\hline $\mathrm{LDH}^{\mathrm{a}}$ & $4: 1$ & 7.67 & 3.042 & $*$ & - & - & - \\
\hline $\mathrm{LDH}^{\mathrm{b}}$ & $2: 1$ & 8.66 & 3.037 & $\mathrm{LDH}^{\mathrm{b}}$ & $2: 1$ & 8.87 & 3.042 \\
\hline $\mathrm{LDH}^{\mathrm{b}}$ & $3: 1$ & 8.66 & 3.038 & LDH10 ${ }^{b}$ & $3: 1$ & 8.87 & 3.047 \\
\hline $\mathrm{LDH}^{\mathrm{b}}$ & $4: 1$ & 8.66 & 3.041 & $\mathrm{LDH}_{11}{ }^{\mathrm{b}}$ & $4: 1$ & 8.80 & 3.054 \\
\hline
\end{tabular}

${ }^{\mathrm{a}}$ Intercalating anion is carbonate; ${ }^{\mathrm{b}}$ Intercalating anion is nitrate and ${ }^{\mathrm{c}}$ Calculation of this parameter is based on the average distance between the metal cations $\left(\mathrm{a}=2 \mathrm{~d}_{110}\right)$. ${ }^{*} \mathrm{It}$ was not possible to synthesize the solid $\mathrm{Zn} / \mathrm{Al}$ $4: 1$ with $\mathrm{CO}_{3}{ }^{2-}$ in a pure phase.

X-ray powder diffraction (Figure 7) aided characterization of the solids. The calculated basal distances agreed with literature data on this class of compounds and were typical of an LDH solid bearing intercalated carbonate $(\sim 7.65 \AA)$ (Figure 7a) or nitrate $(\sim 8.79 \AA)$ (Figure 7b) ions [94-96]. Recently, the structure of LDHs have been obtained also by X-ray [97] or electron diffraction methods [98].

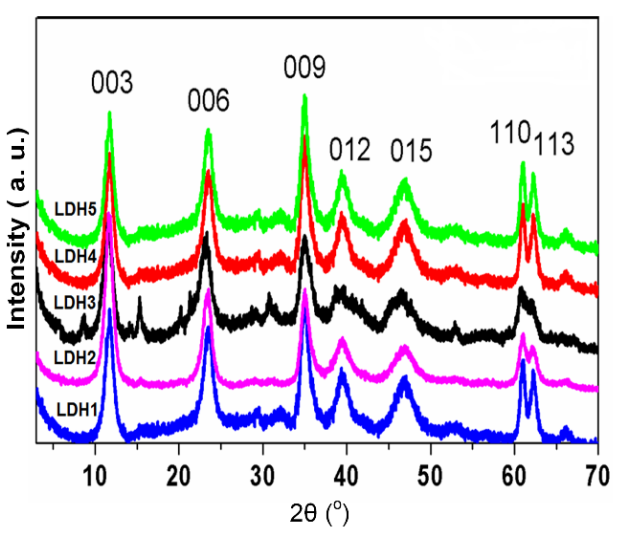

(a)

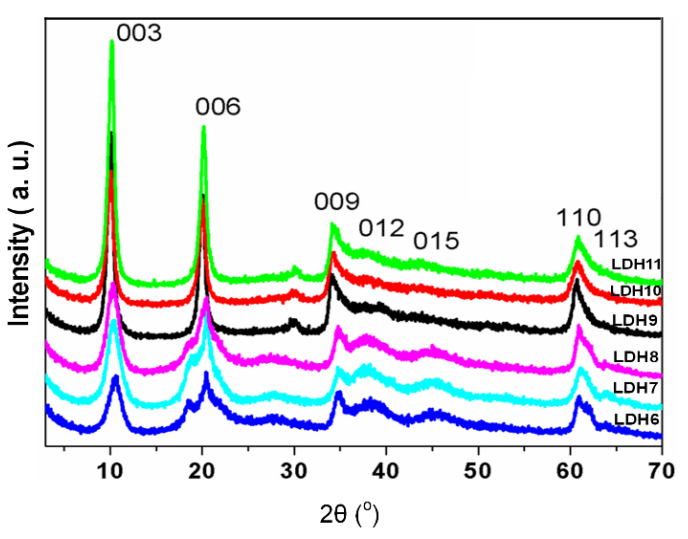

(b)

Figure 7. XRD patterns (powder) of the prepared LDHs intercalated with: (a) $\mathrm{CO}_{3}{ }^{2-}$; (b) $\mathrm{NO}_{3}{ }^{-}$.

The cell parameters " $\mathrm{a}$ " referred to the distance between the metal ions present in the LDH layer. Table 2 lists the values for this parameter and revealed an increasing trend higher $\mathrm{M}^{2+} / \mathrm{M}^{3+}$ ratio increased the ionic radius of each $\mathrm{M}^{2+}$ (the ionic radius of $\mathrm{Mg}^{2+}$ and $\mathrm{Zn}^{2+}$ is $0.74 \AA$ and $0.66 \AA$, respectively).

Infrared analyses of the synthesized LDHs (Supplementary Data, Figure S1) evidenced the typical vibrational bands profile of these materials. The band at $3434 \mathrm{~cm}^{-1}$ was related to stretching of the $\mathrm{O}-\mathrm{H}$ bond in the hydroxyl groups of the layers and the co-intercalated water molecules. The band at $1625 \mathrm{~cm}^{-1}$ was due to angular deformation of water molecules. The bands in the region below $600 \mathrm{~cm}^{-1}$ were characteristic of metal-oxygen $(\mathrm{M}-\mathrm{O})$ stretching. The spectra of the LDHX solids 
$(X=1-5)$ displayed the typical bands of carbonate ions at $1366 \mathrm{~cm}^{-1}$ and $1636 \mathrm{~cm}^{-1}$. The solids also featured a band at $1382 \mathrm{~cm}^{-1}$, characteristic of nitrate ions, which was more pronounced in the spectrum of LDH4. This small contamination with nitrate ions probably resulted from the starting chemicals (nitrate salts).

In the spectra of the LDHX solids $(X=6-11)$, bands ascribed to nitrate ion appeared at $1382 \mathrm{~cm}^{-1}$ and $1023 \mathrm{~cm}^{-1}$. In the same spectra, a shoulder at $1366 \mathrm{~cm}^{-1}$ indicated that these compounds also contained traces of carbonate ions [94,96].

Thermogravimetric analysis (TGA) helped to estimate the water content (physisorbed and intercalated) and the chemical composition of the solids based on the residual oxides content (Supplementary Data, Figure S2) (Table 3) [99].

Table 3. Percentage (\%) of $\mathrm{H}_{2} \mathrm{O}$ loss from LDHs and comparison of the theoretical and calculated $\mathrm{M}^{2+} / \mathrm{M}^{3+}$ ratios.

\begin{tabular}{|c|c|c|c|c|c|c|c|}
\hline \multirow{2}{*}{$\mathrm{LDH}-\mathrm{CO}_{3}$} & \multirow{2}{*}{$\% \mathrm{H}_{2} \mathrm{O}$} & \multicolumn{2}{|c|}{$\mathbf{M}^{2+} / \mathbf{M}^{3+}$ Molar Ratio } & \multirow{2}{*}{${\mathrm{LDH}-\mathrm{NO}_{3}}$} & \multirow{2}{*}{$\% \mathrm{H}_{2} \mathrm{O}$} & \multicolumn{2}{|c|}{$\mathbf{M}^{2+} / \mathbf{M}^{3+}$ Molar Ratio } \\
\hline & & Calculated & Theoretical & & & Calculated & Theoretical \\
\hline LDH1 & 19.9 & 2.3 & 2 & LDH6 & 7.08 & 1.8 & 2 \\
\hline LDH2 & 7.41 & 3.5 & 3 & LDH7 & 3.84 & 3.3 & 3 \\
\hline LDH3 & 9.44 & 4.6 & 4 & LDH8 & 6.33 & 4.4 & 4 \\
\hline LDH4 & 3.5 & 2.2 & 2 & LDH9 & 4.38 & 2.0 & 2 \\
\hline LDH5 & 8.82 & 3.5 & 3 & LDH10 & 2.84 & 3.4 & 3 \\
\hline & & & & LDH11 & 1.16 & 4.5 & 4 \\
\hline
\end{tabular}

Table 4 summarizes the solids resulting from MnP immobilization on the different LDH solids (named MnP-LDHX, where MnP refers to [Mn(TDFSPP)] and X refers to the prepared LDH).

Table 4. Loading values calculated for the solids obtained after immobilization of $100 \% \mathrm{MnP}$ on the prepared LDHs ${ }^{\text {a }}$.

\begin{tabular}{|c|c|c|c|}
\hline $\mathrm{LDH}-\mathrm{CO}_{3}$ & Loading ${ }^{b} / 10^{-6} \mathbf{~ m o l} \cdot \mathrm{g}^{-1}$ & $\mathrm{LDH}_{-\mathrm{NO}_{3}}$ & Loading $^{\mathbf{b}} / 10^{-6} \mathbf{m o l} \cdot \mathrm{g}^{-1}$ \\
\hline LDH1 (Mg/Al-2:1) & 5.7 & LDH6 (Mg/Al—2:1) & 4.0 \\
\hline LDH2 (Mg/Al-3:1) & 4.6 & LDH7 (Mg/Al-3:1) & 4.0 \\
\hline LDH3 (Mg/Al-4:1) & 6.4 & LDH8 (Mg/Al一4:1) & 4.1 \\
\hline LDH4 (Zn/Al-2:1) & 5.9 & LDH9 (Zn/Al-2:1) & 4.4 \\
\hline \multirow[t]{2}{*}{ LDH5 (Zn/Al-3:1) } & 5.3 & LDH10 (Zn/Al-3:1) & 4.0 \\
\hline & & LDH11 (Zn/Al-4:1) & 4.1 \\
\hline
\end{tabular}

\footnotetext{
${ }^{a} \mathrm{MnP}$ immobilization was conducted by dispersing around $700 \mathrm{mg}$ of the LDH solid in $10 \mathrm{~mL}$ of solvent and $4 \mathrm{mg}$ of MnP. This suspension was magnetically stirred for $2 \mathrm{~h}$. Then, the resulting solid was centrifuged and washed with methanol and the supernatant was analyzed by UV-Vis spectroscopy in order to quantify the MnP that could have been removed from the matrix by leaching. The loading values were determined indirectly. The light yellow solids MnP-LDH were dried at $60^{\circ} \mathrm{C} .{ }^{\mathrm{b}}$ Loading $=$ mol of MnP per 1 gram of solid obtained in the immobilization process.
}

Figure 8 brings the UVVIS results obtained for the prepared solids. Figure $8 \mathrm{~b}$ depicts the UVVIS spectrum (in Nujol mull) of immobilized MnP-LDH3. The spectra displayed the typical MnP Soret band near $463 \mathrm{~nm}$ [84], confirming MnP immobilization on the solid. Lack of changes in the basal distance, as revealed by X-ray analysis (data not shown), indicated MnP surface immobilization and excluded MnP intercalation between the LDH layers. All the prepared solids presented the same behavior.

Figure 8a depicts the UVVIS spectrum of the methanolic MnP solution. The Soret band appeared at $457 \mathrm{~nm}$. The UVVIS spectra of the supernatant collected after the immobilization process (Figure 8c) confirmed MnP immobilization close to $100 \%$ for all the prepared solids. 


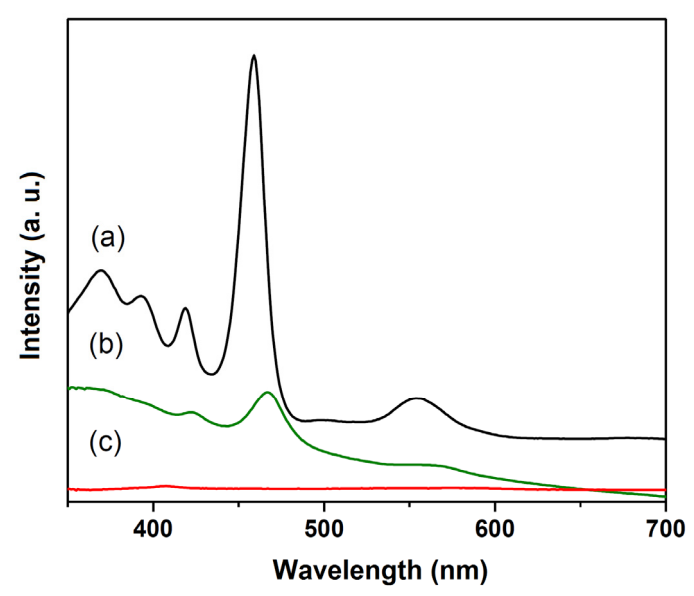

Figure 8. UVVIS spectra: (a) Methanolic MnP solution; (b) Solid Nujol emulsion of MnP-LDH3; (c) Supernatant collected after the immobilization process.

We excluded the interaction of the MnP with the layered crystal edges, which was negligible in terms of quantity. Then, we attempted to understand the mode of MnP immobilization on the surface of the LDH support by performing some calculations.

Considering the ideal $\mathrm{M}^{+2} / \mathrm{M}^{+3}$ molar ratios used in the synthesis, where the $\mathrm{M}^{+3}$ concentration led to a proportional concentration of positive charges on the surface of the layered crystals, we expected that the tetranegatively charged $\mathrm{MnP}$ would establish different modes of interaction.

Because both adjacent layers should share the charges, the positive charge on the layer surface should be half of the value and the distances between charges should be twice the distance between the $\mathrm{M}^{+3}$ cations. This calculation was based on the values found for the cell "a" parameter (Table 2), which measures the distance between the metal ions present in the layers (Table 5). As for $d_{1,2}$, it represents the distance between the numbered purple balls labeled 1 and 2 in Figure 9. The same representation applies for the distances between purple balls labeled 2 and $3\left(\mathrm{~d}_{2,3}\right), 3$ and $4\left(\mathrm{~d}_{3,4}\right), 4$ and $1\left(\mathrm{~d}_{4,1}\right), 1$ and $3\left(\mathrm{~d}_{1,3}\right)$ and 2 and $4\left(\mathrm{~d}_{2,4}\right)$.

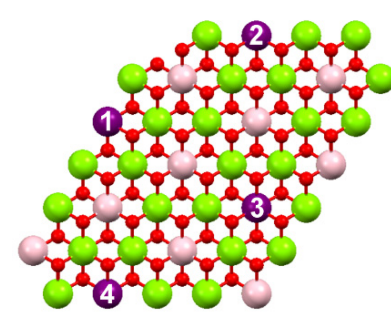

(a)

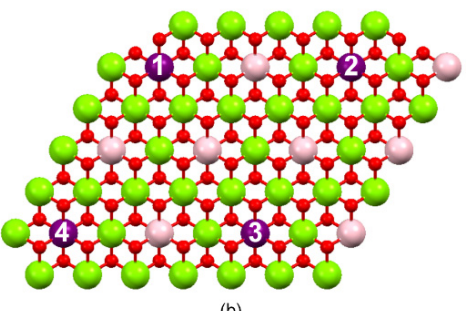

(b)

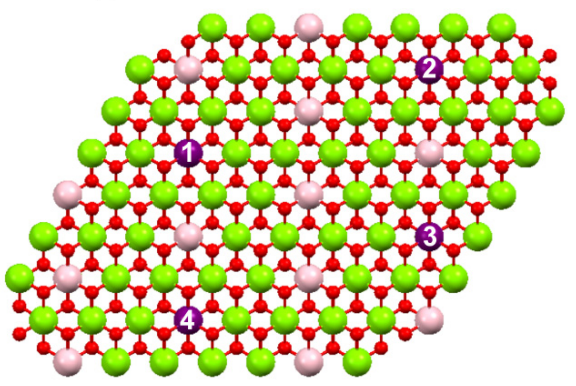

(c)

Figure 9. Schematic representation of the structure of the $\mathrm{LDH}$ prepared at $\mathrm{Mn}^{2+} / \mathrm{M}^{3+}$ molar ratio of: (a) 2:1; (b) 3:1; (c) 4:1. The pink and purple balls represent the species $\mathrm{M}^{3+}$, the green balls represent the species $\mathrm{M}^{2+}$ and the red balls represent the oxygen atoms from the hydroxyl ions. Figure built with the aid of the Mercury ${ }^{\circledR}$ free software. 
Software Hyperchem ${ }^{\circledR}$ helped to determine the distances between the $\mathrm{MnP}$ negative charges $\left(\mathrm{SO}_{3}{ }^{-}\right)$ (Figure 10a) by optimization of the $\mathrm{MnP}$ structure. Figure $10 \mathrm{~b}-\mathrm{d}$ show a schematic representation of the possible modes of MnP interaction with the layered crystal surface.

Table 5. Calculated distances between the positive charges of the LDH layers, multiplied by two.

\begin{tabular}{cccccccc}
\hline LDHX Solid & $\mathbf{d}_{\mathbf{1 , 2}}(\AA)$ & $\mathbf{d}_{\mathbf{2 , 3}}(\AA)$ & $\mathbf{d}_{\mathbf{3 , 4}}(\AA)$ & $\mathbf{d}_{\mathbf{4 , \mathbf { 1 }}}(\AA)$ & $\mathbf{d}_{\mathbf{1 , 3}}(\AA)$ & $\mathbf{d}_{\mathbf{2 , 4}}(\AA)$ & As Shown in \\
\hline LDH1 (Mg/Al-2:1) & 10.52 & 10.52 & 10.52 & 10.52 & 10.52 & 10.52 & Figure 10b \\
LDH2 (Mg/Al-3:1) & 12.15 & 12.15 & 12.15 & 12.15 & 12.15 & 21.04 & Figure 10c \\
LDH3 (Mg/Al-4:1) & $16.10^{*}$ & 10.54 & $16.10^{*}$ & 10.54 & $16.10 *$ & 27.88 & Figure 10d \\
LDH4 (Zn/Al-2:1) & 10.53 & 10.53 & 10.53 & 10.53 & 10.53 & 10.53 & Figure 10b \\
LDH5 (Zn/Al-3:1) & 12.21 & 12.21 & 12.21 & 12.21 & 12.21 & 21.14 & Figure 10c \\
LDH6 (Mg/Al-2:1) & 10.52 & 10.52 & 10.52 & 10.52 & 10.52 & 10.52 & Figure 10b \\
LDH7 (Mg/Al-3:1) & 12.15 & 12.15 & 12.15 & 12.15 & 12.15 & 21.05 & Figure 10c \\
LDH8 (Mg/Al-4:1) & $16.09 *$ & 10.53 & $16.09 *$ & 10.53 & $16.09 *$ & 27.87 & Figure 10d \\
LDH9 (Zn/Al-2:1) & 10.54 & 10.54 & 10.54 & 10.54 & 10.54 & 10.54 & Figure 10b \\
LDH10 (Zn/Al-3:1) & 12.19 & 12.19 & 12.19 & 12.19 & 12.19 & 21.11 & Figure 10c \\
LDH11 (Zn/Al-4:1) & $16.16^{*}$ & 10.58 & $16.16^{*}$ & 10.58 & $16.16^{*}$ & 27.99 & Figure 10d \\
\hline
\end{tabular}

* Distances coincident with the found value for the distance between the negative charges of MnP.

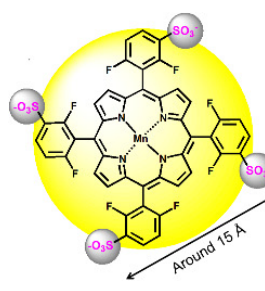

(a)

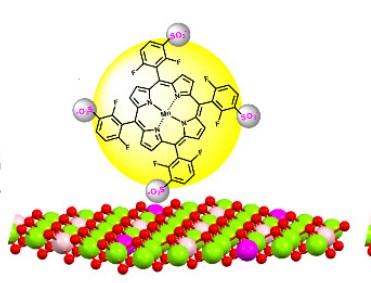

(b)

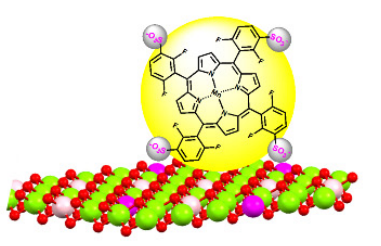

(c)

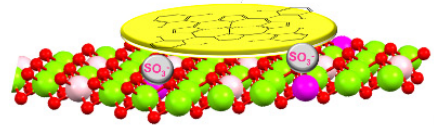

(d)

Figure 10. Schematic representation of the possible modes of MnP (yellow ball interaction with the LDH surface: (a) MnP; (b) MnP interacts only via one negative charge; (c) via two negative charges; (d) via four negative charges.

The first proposal (Figure 10d) represents interaction of four negative charges in the MnP with four positive charges in the support layer. For the MnP to immobilize on the LDH in this way, the calculated distances between the positive charges present in the support layer must precisely match the distances between the four MnP negative charges. This limitation allowed us to exclude this arrangement from the formulated hypothesis.

In the second representation (Figure 10c), two MnP negative charges interact with LDH. Values described in Table 5 were based on the distance between two LDH positive charges and on the distance between the $\mathrm{MnP} \mathrm{SO}_{3}{ }^{-}$substituents (negative charges). Analysis of the values of positive charges in the LDH layers presented in Table 5 (indicated by ${ }^{*}$ ) suggested that this kind of interaction (by two charges) was possible for $\mathrm{MnP}$ immobilization on the $\mathrm{LDH}$ prepared at only $\mathrm{M}^{2+} / \mathrm{M}^{3+}$ molar ratio of $4: 1$.

Figure 10b corresponds to yet another proposal for MnP immobilization on the LDH-MnP would be in contact with the LDH surface just via one negative charge. This is probably the most feasible proposal because it only depends on the approach of one opposite charge and dismisses the need to match the distances between the MnP negative charges and the LDH surface layer positive charges.

We evaluated the prepared solids as catalysts for cyclooctene oxidation in an attempt to understand how the $\mathrm{M}^{+2} / \mathrm{M}^{+3}$ molar ratio, the type of intercalated anion (single-charged nitrate and double-charged carbonate), and the mode of MnP immobilization influenced the MnP catalytic activity. Cyclooctene was selected because it is commonly employed as substrate during investigation into the catalytic activity of MPs $[16,17,83,100,101]$. 
Although all the solid catalysts contained the same MnP, they afforded distinct catalytic results (Table 6). Based on Table 6, rationalizing the effect of the support on product yield was not easy. However, analysis of the last column of Table 6, which provided the epoxide yields by excluding the yield obtained for the control reactions (reactions performed with pure LDH without immobilized MnP, Table 6, runs 13-23) revealed some interesting trends in the catalytic behavior of the MnP immobilized on the prepared LDHs. Figure 11 represents these differences and trends better.

Table 6. Results obtained in the epoxidation reactions cyclooctene.

\begin{tabular}{|c|c|c|c|c|c|}
\hline Catalyst & Run & $\begin{array}{c}\text { LDH } \\
\left(\mathrm{M}^{2+} / \mathrm{M}^{3+}\right)\end{array}$ & LDH Anion & $\begin{array}{c}\text { Epoxide Yield } \\
(\%)^{\mathrm{a}}\end{array}$ & $\begin{array}{l}\text { Epoxide Yield } \\
\text { Corrected }^{\mathrm{d}}\end{array}$ \\
\hline $\mathrm{MnP}^{\mathrm{b}}$ & 1 & & & $76.3 \pm 3.8$ & 62.2 \\
\hline MnP-LDH1 & 2 & $2: 1$ & $\mathrm{Mg} / \mathrm{Al}-\mathrm{CO}_{3}$ & $51.3 \pm 3.2$ & 47.3 \\
\hline MnP-LDH2 & 3 & $3: 1$ & $\mathrm{Mg} / \mathrm{Al}-\mathrm{CO}_{3}$ & $71.2 \pm 2.9$ & 64.8 \\
\hline MnP-LDH3 & 4 & $4: 1$ & $\mathrm{Mg} / \mathrm{Al}-\mathrm{CO}_{3}$ & $49.9 \pm 5.7$ & 46.4 \\
\hline MnP-LDH4 & 5 & $2: 1$ & $\mathrm{Zn} / \mathrm{Al}-\mathrm{CO}_{3}$ & $68.2 \pm 4.4$ & 60.3 \\
\hline MnP-LDH5 & 6 & $3: 1$ & $\mathrm{Zn} / \mathrm{Al}-\mathrm{CO}_{3}$ & $77.1 \pm 5.4$ & 71.2 \\
\hline MnP-LDH6 & 7 & $2: 1$ & $\mathrm{Mg} / \mathrm{Al}-\mathrm{NO}_{3}$ & $61.2 \pm 2.6$ & 55.3 \\
\hline MnP-LDH7 & 8 & $3: 1$ & $\mathrm{Mg} / \mathrm{Al}-\mathrm{NO}_{3}$ & $57.6 \pm 3.7$ & 50.4 \\
\hline MnP-LDH8 & 9 & $4: 1$ & $\mathrm{Mg} / \mathrm{Al}-\mathrm{NO}_{3}$ & $50.2 \pm 4.1$ & 44.9 \\
\hline MnP-LDH9 & 10 & $2: 1$ & $\mathrm{Zn} / \mathrm{Al}-\mathrm{NO}_{3}$ & $71.7 \pm 5.2$ & 62.6 \\
\hline MnP-LDH10 & 11 & $3: 1$ & $\mathrm{Zn} / \mathrm{Al}-\mathrm{NO}_{3}$ & $75.0 \pm 3.6$ & 67.6 \\
\hline MnP-LDH11 & 12 & $4: 1$ & $\mathrm{Zn} / \mathrm{Al}-\mathrm{NO}_{3}$ & $73.1 \pm 4.1$ & 65.8 \\
\hline LDH1 & 13 & $2: 1$ & $\mathrm{Mg} / \mathrm{Al}-\mathrm{CO}_{3}$ & $4.0 \pm 3.8$ & - \\
\hline LDH2 & 14 & $3: 1$ & $\mathrm{Mg} / \mathrm{Al}-\mathrm{CO}_{3}$ & $6.4 \pm 2.3$ & - \\
\hline LDH3 & 15 & $4: 1$ & $\mathrm{Mg} / \mathrm{Al}-\mathrm{CO}_{3}$ & $3.5 \pm 4.8$ & - \\
\hline LDH4 & 16 & $2: 1$ & $\mathrm{Zn} / \mathrm{Al}-\mathrm{CO}_{3}$ & $7.9 \pm 6.3$ & - \\
\hline LDH5 & 17 & $3: 1$ & $\mathrm{Zn} / \mathrm{Al}-\mathrm{CO}_{3}$ & $5.9 \pm 4.4$ & - \\
\hline LDH6 & 18 & $2: 1$ & $\mathrm{Mg} / \mathrm{Al}-\mathrm{NO}_{3}$ & $2.5 \pm 5.6$ & - \\
\hline LDH7 & 19 & $3: 1$ & $\mathrm{Mg} / \mathrm{Al}-\mathrm{NO}_{3}$ & $7.2 \pm 2.2$ & - \\
\hline LDH8 & 20 & $4: 1$ & $\mathrm{Mg} / \mathrm{Al}-\mathrm{NO}_{3}$ & $5.3 \pm 3.7$ & - \\
\hline LDH9 & 21 & $2: 1$ & $\mathrm{Zn} / \mathrm{Al}-\mathrm{NO}_{3}$ & $9.1 \pm 5.3$ & - \\
\hline LDH10 & 22 & $3: 1$ & $\mathrm{Zn} / \mathrm{Al}-\mathrm{NO}_{3}$ & $7.4 \pm 6.1$ & - \\
\hline LDH11 & 23 & $4: 1$ & $\mathrm{Zn} / \mathrm{Al}-\mathrm{NO}_{3}$ & $7.3 \pm 4.3$ & - \\
\hline Control $^{c}$ & 24 & & & $14.1 \pm 1.3$ & - \\
\hline
\end{tabular}

${ }^{\text {a }}$ Reaction yield (in percentage) based on the quantity of oxidant (iodosylbenzene) used during the reaction;

${ }^{\mathrm{b}}$ homogeneous catalysis. Epoxide $=$ Cyclooctene oxide; ${ }^{\mathrm{c}}$ Control reaction: reaction performed with iodosylbenzene and cyclooctene only under the same reaction conditions used for run 1; ${ }^{\mathrm{d}}$ Epoxide yield, corrected $=($ Epoxide yield $\%$-epoxide yield $\%$ obtained for the respective LDH without MnP $)$. For the homogeneous catalysis $=(\%$ run $1-\%$ run 24$)$.

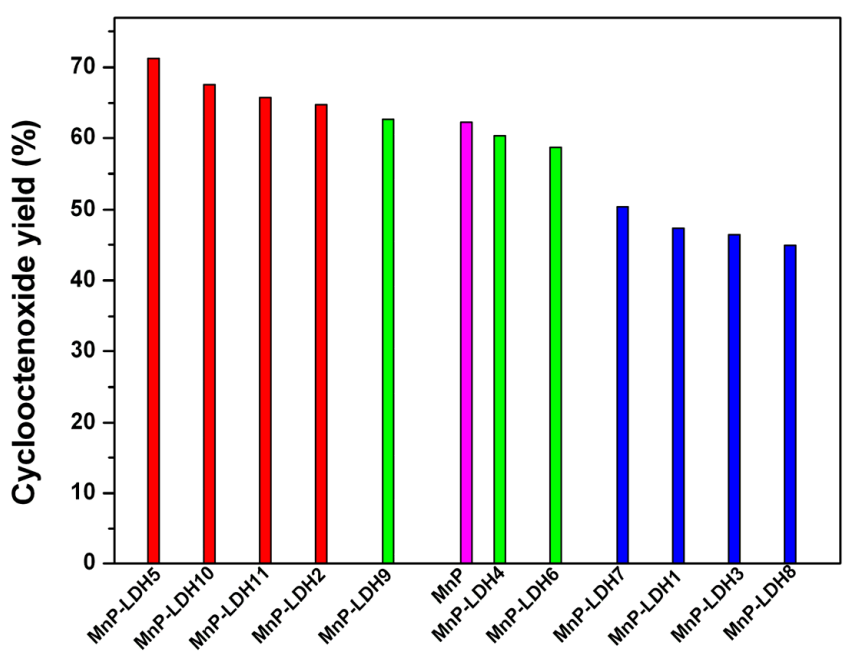

Figure 11. Comparison of the product yield obtained with MnP during homogeneous cyclooctene epoxidation (magenta bar) and of the product yield obtained for each of the prepared solid catalysts (MnP-LDHX). The yield attributed to the control reaction has been subtracted in all cases. 
MnP immobilization on LDH5, LDH10, LDH11, and LDH2 (red bars in Figure 11) produced solid catalysts that gave higher product yields than the same MnP during homogeneous catalysis (magenta bar in Figure 11). Most of these prepared LDHs contained high $\mathrm{Zn} / \mathrm{Al}$ molar ratio. The intercalated anion did not seem to affect the catalytic results. The only exception to this trend was LDH2, which corresponded to a $\mathrm{Mg} / \mathrm{Al}-\mathrm{LDH}$ but had the same $\mathrm{M}^{2+} / \mathrm{M}^{3+}$ molar ratio as LDH5 (3:1). Indeed, the catalytic result achieved with MnP-LDH2 was on the borderline between the red and the green group in Figure 11. All the solids in the red group gave rise to higher catalytic performance as compared to the $\mathrm{MnP}$ in homogeneous solution.

The group of green bars in Figure 11 represented the solid catalysts that gave product yield similar to the yield obtained with the same MnP during homogeneous catalysis, namely MnP-LDH9 (Zn/Al 2:1), MnP LDH4 (Zn/Al 2:1), and, at the borderline between the green and blue groups, MnP-LDH6 $(\mathrm{Mg} / \mathrm{Al} 2: 1)$. The catalysts in the green group showed that MnP immobilization did not translate into the catalytic advantage observed in the case of the catalysts in the red group. The only advantage of $\mathrm{MnP}$ immobilization in the green group was prevention of MnP catalytic activity loss and possibility of catalyst recovery and reuse after the first cycle.

Finally, the blue group corresponded to the solid catalysts that afforded lower epoxidation yield than the yield furnished by the MnP during homogeneous catalysis, more specifically MnP-LDH7 (Mg/Al 3:1), MnP-LDH1 (Mg/Al 2:1), MnP-LDH3 (Mg/Al 4:1), and MnP-LDH8 (Mg/Al 4:1). All the LDHs in this group contained $\mathrm{Mg}^{2+}$ in their compositions, showing that this ion abated the MnP catalytic performance irrespective of the intercalated anion and of the $\mathrm{M}^{2+} / \mathrm{M}^{3+}$ molar ratio.

These results suggested that the characteristics of the $\mathrm{MnP} /$ support catalytic system depended on the $\mathrm{LDH}$ and on the kind of interaction established between the MnP and the support. At a first glance, one might think that the access of reagents to the $\mathrm{MnP}$ was a function of the divalent metal present in the LDH.

$\mathrm{M}^{2+} / \mathrm{M}^{3+}$ molar ratios of 3:1 in the $\mathrm{LDH}$ seemed to favor the MnP catalytic activity. This may have been related to the way that the porphyrin attached to the LDH surface and showed that changes in support composition may have affected the approach of the substrate to the catalytically active center. This effect was more evident for $\mathrm{Zn} / \mathrm{Al}-\mathrm{LDH}$.

In general, $\mathrm{LDH}$ containing $\mathrm{Zn}^{2+}$ ions furnished the best catalytic results. The effect of zinc versus magnesium is not easy to explain, and studies on how different LDH compositions impact the catalytic oxidation results are rare.

Zhang et al. recently prepared gold nanoclusters (AuNCs) supported on $\mathrm{M}_{3} \mathrm{Al}-\mathrm{LDHs}\left(\mathrm{M}=\mathrm{Mg}^{2+}\right.$, $\mathrm{Ni}^{2+}, \mathrm{Co}^{2+}$ ) and used these solids to catalyze aerobic 1-phenylethanol oxidation under solvent-free conditions [102]. The AuNCs $/ \mathrm{M}_{3} \mathrm{Al}-\mathrm{LDH}$ (where $\mathrm{M}=\mathrm{Ni}^{2+}$ or $\mathrm{Co}^{2+}$ ) catalysts presented higher alcohol oxidation activity than AuNCs $/ \mathrm{Mg}_{3} \mathrm{Al}-\mathrm{LDH}$. Many factors contributed to these results: (i) generation of a larger amount of hydroxyl groups in the presence of $\mathrm{Ni}^{2+}$ and $\mathrm{Co}^{2+}$ during preparation of the $\mathrm{M}_{3} \mathrm{Al}-\mathrm{LDH}$ support, which implied that Brønsted basic sites existed in the AuNCs $/ \mathrm{M}_{3} \mathrm{Al}-\mathrm{LDH}$ catalysts; (ii) high acidity of the LDH surface in the presence of AuNCs; (iii) critical effect of the metal components in the LDH supports on the electronic structure of AuNCs; (iv) more negatively charged AuNCs in AuNCs $/ \mathrm{Ni}_{3} \mathrm{Al}-\mathrm{LDH}$ and AuNCs $/ \mathrm{Co}_{3} \mathrm{Al}-\mathrm{LDH}$; (v) larger electronegativity of the transition metals $\mathrm{Ni}$ and $\mathrm{Co}$ as compared to $\mathrm{Mg}$, which may have facilitated electron transfer from the support to the AuNCs, resulting in more electron-rich Au cores in AuNCs/Ni $\mathrm{Al}-\mathrm{LDH}$ and $\mathrm{AuNCs} / \mathrm{Co}_{3} \mathrm{Al}-\mathrm{LDH}$ than in AuNCs $/ \mathrm{Mg}_{3} \mathrm{Al}-\mathrm{LDH}$. The authors claimed that all these factors elicited a synergistic effect between the LDH and AuNCs, resulting in better catalytic performance for AuNCs $/ \mathrm{Ni}_{3} \mathrm{Al}-\mathrm{LDH}$ and $\mathrm{AuNCs} / \mathrm{Co}_{3} \mathrm{Al}-\mathrm{LDH}$ during the oxidation reaction.

In another recent example, Sun et al. [103] prepared a structured catalyst by immobilizing a cobalt phthalocyanine tetrasulfonate ( $\mathrm{CoPcS}$ ) onto multimetallic oxides of the $\mathrm{Mg}$, Ni/ Al-MMO type (obtained by thermal decomposition of $\mathrm{Mg}$, Ni/Al-LDH) with tunable basicity. Their purpose was to enhance the synergistic effect between the active center ( $\mathrm{CoPcS})$ and the basicity of the support to the maximal extent; they used the Mercaptan Sweetening catalytic reaction via oxidation of 1-octanethiol 
to the corresponding disulfide as model reaction [101]. Changes in the relative content of $\mathrm{Mg}^{2+}$ and $\mathrm{Ni}^{2+}$ in the $\mathrm{LDH}$ precursor used to prepare the support $\mathrm{Mg}, \mathrm{Ni} / \mathrm{Al}-\mathrm{MMO}$ by thermal decomposition conveniently tuned the basicity and the number of moderately basic sites in the solid designated $\mathrm{CoPcS} / \mathrm{Mg}, \mathrm{Ni} / \mathrm{Al}-\mathrm{MMO}$. Alterations in the $\mathrm{Mg} / \mathrm{Ni}$ molar ratios increased the conversion value: $\mathrm{Mg} / \mathrm{Ni}$ molar ratio of 1.16 gave maximum conversion $(93 \%)$. The authors claimed that the synergistic effect between the oxidation center (CoPcS) and the large number of moderate basic sites $(0.49 \mathrm{mmol} / \mathrm{g}$, determined by $\mathrm{CO}_{2}$-TPD) present in the catalyst support was optimal at this $\mathrm{Mg} / \mathrm{Ni}$ molar ratio. Thereafter, conversion values decreased. The authors concluded that the intrinsic mechanism of the synergistic should be rather complicated, which is the reason why it is under investigation in their research lab.

Together, these few examples corroborated our preliminary results on the active influence of the catalyst support on the oxidative catalytic activity of the $\mathrm{MnP}$ during cyclooctene oxidation.

The possible effect of the water present in the interlayer space and outer surface of the prepared LDHs should not be ignored. Percentage $\mathrm{H}_{2} \mathrm{O}$ mass loss in the solid LDHs without MnP (Table 3) and the cyclooctene oxidation reaction yields achieved for the respective solids (Table 6) pointed to a dependence of product yield on the quantity of water in the solid. In other words, water might affect the catalytic behavior of the material in these reactions [103].

In conclusion, the catalytic results presented here suggested that the catalytic properties of the investigated MnP-LDH solids strongly depended on the nature of the LDH support, the $\mathrm{M}^{+2} / \mathrm{M}^{+3}$ molar ratio, and the intercalated anion, which consequently influenced the mode of negatively charged MnP immobilization on the layered crystals surface.

\section{Conclusions}

Layered compounds are a very interesting class of compounds for the immobilization of porphyrins, metalloporphyrins (MP), phthalocyanines, and other macrocyclic complexes. Immobilization may occur on the layered surface or between the layers (intercalation).

Layered double hydroxides (LDHs) have long been investigated as supports for MP immobilization. In recent years, new catalysts have been developed by diverse strategies like LDH exfoliation, LDH restacking, low-polar MP encapsulation into LDH layers intercalated with dodecyl sulfonate, and MP entrapment into LDHs anchored on magnetic particles. The latter alternative facilitates catalyst recovery and reuse because a simple magnet can separate the catalyst from the reaction medium.

Some layered hydroxide salts (LHSs) such as zinc hydroxide nitrate (ZHN) and zinc hydroxide chloride (ZHC) display distinct behavior regarding MP immobilization, including modified selectivity of the supported catalyst during cyclohexane oxidation, which indicates that the support influences the oxidation mechanism. In addition, zinc oxides derived from LHSs exert cooperative effects on immobilized MP during catalytic toluene oxidation.

MPs immobilized on LHSs remain unexplored. Many LHSs can be used for investigative purposes. LHSs may contain $\mathrm{Cu}^{2+}, \mathrm{Co}^{2+}, \mathrm{Ni}^{2+}, \mathrm{Mn}^{2+}$, and mixtures of two or even three different divalent metals as well as intercalated hydrophyllic anions (such as $\mathrm{NO}_{3}{ }^{-}, \mathrm{Cl}^{-}, \mathrm{SO}_{4}{ }^{2-}$, and $\mathrm{CO}_{3}{ }^{2-}$ ) or hydrophobic interlayer anions (like carboxylates, sulfonates, and phosphates). In the case of organic divalent anionic species bearing one negative charge at the end of the ion, grafting of the species to the support is also possible, and pillared derivatives with high surface area may arise. If by only changing the interlayer anion in the support bearing the anionic FeP (e.g., ZHN and ZHC) greatly modifies the oxidation mechanism, more surprises may lie ahead for MP immobilization on LHSs. Moreover, MP immobilization on LHS oxide derivatives can aid the development of novel catalysts for oxidation or photocatalytic reactions.

This work also reported on immobilization of a manganese(III) porphyrin [Mn(TDFSPP)] (MnP) on different LDHs prepared with variable $\mathrm{M}^{+2} / \mathrm{M}^{+3}$ molar ratios $\left(\mathrm{M}^{+2}=\mathrm{Mg}^{+2}\right.$ or $\mathrm{Zn}^{+2}$ and $\left.\mathrm{M}^{+3}=\mathrm{Al}^{+3}\right)$ and different intercalated anions (monovalent nitrate and divalent carbonate) to investigate how 
these variables affected MnP immobilization and catalytic performance. Preliminary catalytic results suggested that composition of the prepared LDHs seemed to impact the catalytic performance of the immobilized MnP. Distinct divalent metals $\left(\mathrm{Mg}^{+2}\right.$ or $\left.\mathrm{Zn}^{+2}\right)$ in the LDH elicited different results. The $\mathrm{M}^{2+} / \mathrm{M}^{3+}$ molar ratio in the support correlated positively with the catalytic activity. Probably, changes in the basicity of the support and not the spacing between the positive charges in the layers (i.e., the MP mode of immobilization) influenced the MnP catalytic activity. This proposition is currently under investigation in our research lab.

Supplementary Materials: The following are available online at www.mdpi.com/link/1420-3049/21/3/291/s1, Figure S1: Infrared spectra of the prepared LDHs intercalated with: (a) $\mathrm{CO}_{3}{ }^{2-}$; (b) $\mathrm{NO}_{3}{ }^{-}$.; Figure S2: Thermogravimetric analysis of the synthetized LDHs.

Acknowledgments: The authors thank Conselho Nacional de Desenvolvimento Científico e Tecnológico (CNPq), Coordenação de Aperfeiçoamento de Pessoal de Nível Superior (CAPES), Fundação Araucária, Fundação da Universidade Federal do Paraná (FUNPAR), and Universidade Federal do Paraná (UFPR) for financial support.

Author Contributions: Shirley Nakagaki is the group head and major responsible for the idealization and writing of the manuscript. Karen Mary Mantovani, with Shirley Nakagaki and Fernando Wypych, conceived, designed and performed the experiments. Karen Mary Mantovani also contributes in Layered Double Hydroxide review. Guilherme Sippel Machado contributed writing part of introduction and with the review of metalloporphyrin immobilized on layered hydroxide salts and oxides derived from LHS, and with general revision of the article. Kelly Aparecida Dias de Freitas Castro contributed writing part of introduction and part of the LDH review since she worked with this layered solid in that PhD thesis. Fernando Wypych also contributes with layered compounds introduction part and analysis and discussion of the experimental results presented in the manuscript.

Conflicts of Interest: The authors declare no conflict of interest.

\section{References}

1. Milgrom, L.R. The Colours of Life; Oxford University Press: New York, NY, USA, 1997; p. 93.

2. Kadish, K.; Smith, K.; Guillard, R. Applications of Porphyrins and Metalloporphyrins to materials chemistry. In The Porphyrins Handbook; Chou, J.H., Nalwa, H.S., Kosal, M.E., Rakow, N.A., Suslick, K.S., Eds.; Academic Press: New York, NY, USA, 1999; Volume 6, p. 44.

3. Singh, S.; Aggarwal, A.; Thompson, S.; Tomé, J.P.; Zhu, X.; Samaroo, D.; Vinodu, M.; Gao, R.; Drain, C.M. Synthesis and photophysical properties of thioglycosylated-chlorins, isobacteriochlorins and bacteriochlorins for bioimaging and diagnostics. Bioconj. Chem. 2010, 21, 2136-2146. [CrossRef] [PubMed]

4. Castro, K.A.D.F.; Simões, M.M.Q.; Neves, M.G.P.M.S.; Wypych, F.; Cavaleiro, J.A.S.; Nakagaki, S. Glycol metalloporphyrin derivatives in solution or immobilized on LDH and silica: Synthesis, characterization and catalytic features in oxidation reactions. Catal. Sci. Technol. 2014, 4, 129-141. [CrossRef]

5. Mansuy, D. A brief history of the contribution of metalloporphyrin models to cytochrome P450 chemistry and oxidation catalysis. C. R. Chim. 2007, 10, 392-413. [CrossRef]

6. Groves, J.T.; Haushalter, R.C.; Nakamura, M.; Nemo, T.E.; Evans, B.J. High-valent iron-porphyrin complexes related to peroxidase and cytochrome P-450. J. Am. Chem. Soc. 1981, 103, 2884-2886. [CrossRef]

7. Meunier, B.; de Visser, S.P.; Shaik, S. Mechanism of oxidation reactions catalyzed by cytochrome P450 enzymes. Chem. Rev. 2004, 104, 3947-3980. [CrossRef] [PubMed]

8. Simões, M.M.Q.; de Paula, R.; Neves, M.G.P.M.S.; Cavaleiro, J.A.S. Metalloporphyrins in the biomimetic oxidative valorization of natural and other organic substrates. J. Porph. Phthal. 2009, 13, 589-596. [CrossRef]

9. Denisov, I.G.; Makris, T.M.; Sligar, S.G.; Schlichting, I. Structure and chemistry of cytochrome P450. Chem. Rev. 2005, 105, 2253-2277. [CrossRef] [PubMed]

10. Groves, J.T.; Nemo, T.E.; Myers, R.S. Hydroxylation and epoxidation catalyzed by iron-porphine complexes. Oxygen transfer from iodosylbenzene. J. Am. Chem. Soc. 1979, 101, 1032-1033. [CrossRef]

11. Bedioui, F. Zeolite-encapsulated and clay-intercalated metal porphyrin, phthalocyanine and Schiff-base complexes as models for biomimetic oxidation catalysts: An overview. Coord. Chem. Rev. 1995, 144, 39-68. [CrossRef]

12. Suslick, K.S.; Bhyrappa, P.; Chou, J.H.; Kosal, M.E.; Nakagaki, S.; Smithenry, D.W.; Wilson, S.R. Microporous porphyrin solids. Acc. Chem. Res. 2005, 38, 283-291. [CrossRef] [PubMed] 
13. Bolzon, L.B.; Airoldi, H.R.; Zanardi, F.B.; Granado, J.G.; Iamamoto, Y. Metalloporphyrin-functionalized hexagonal mesoporous silica: Synthesis, structural properties and catalytic activity as cytochrome P450 model. Microporours Mesoporous Mater. 2013, 168,37-45. [CrossRef]

14. Evans, S.; Smith, J.R.L. The oxidation of ethylbenzene by dioxygen catalysed by supported iron porphyrins derived from iron(III) tetrakis(pentafluoro-phenyl)porphyrin. J. Chem. Soc. Perkin Trans. 2001, 2, 174-180. [CrossRef]

15. Made, A.W.; van der Smeets, J.W.H.; Nolte, R.J.M.; Drenth, W. Olefin epoxidation by a mono-oxygenase model: Effect of site isolation. J. Chem. Soc. Chem. Commun. 1983. [CrossRef]

16. Machado, G.S.; de Lima, O.J.; Ciuffi, K.J.; Wypych, F.; Nakagaki, S. Iron(III) porphyrin supported on metahalloysite: An efficient and reusable catalyst for oxidation reactions. Catal. Sci. Technol. 2013, 3, 1094-1101. [CrossRef]

17. Papacídero, A.T.; Rocha, L.A.; Caetano, B.L.; Molina, E.; Sacco, H.C.; Nassar, E.J.; Martinelli, Y.; Mello, C.; Nakagaki, S.; Ciuffi, K.J. Preparation and characterization of spherical silica-porphyrin catalysts obtained by the sol-gel methodology. Colloids Surf. A 2006, 275, 27-35. [CrossRef]

18. Martinez-Lorente, M.A.; Battioni, P.; Kleemiss, W.; Bartoli, J.F.; Mansuy, D. Manganese porphyrins covalently bound to silica and montmorillonite $\mathrm{Kl} 0$ as efficient catalysts for alkene and alkane oxidation by hydrogen peroxide. J. Mol. Catal. A Chem. 1996, 113, 343-353. [CrossRef]

19. Nakagaki, S.; Machado, G.S.; Halma, M.; Marangon, A.A.S.; Castro, K.A.D.F.; Mattoso, N.; Wypych, F. Immobilization of iron porphyrins in tubular kaolinite obtained by an intercalation/delamination procedure. J. Catal. 2006, 242, 110-117. [CrossRef]

20. Machado, G.S.; Castro, K.A.D.F.; Wypych, F.; Nakagaki, S. Immobilization of metalloporphyrins into nanotubes of natural halloysite toward selective catalysts for oxidation reactions. J. Mol. Catal. A Chem. 2008, 283, 99-107. [CrossRef]

21. Halma, M.; Bail, A.; Wypych, F.; Nakagaki, S. Catalytic activity of anionic iron(III) porphyrins immobilized on grafted disordered silica obtained from acidic leached chrysotile. J. Mol. Catal. A Chem. 2006, 243, 44-51. [CrossRef]

22. Iamamoto, Y.; Idemori, Y.M.; Nakagaki, S. Cationic ironporphyrins as catalyst in comparative oxidation of hydrocarbons: Homogeneous and supported on inorganic matrices systems. J. Mol. Catal. A Chem. 1995, 99, 187-193. [CrossRef]

23. Gandini, M.E.F.; Neri, C.R.; Vinhado, F.S.; Minorin, T.S.; Nascimento, O.R.; Serra, O.A.; Iamamoto, Y. Modified silicas covalently bounded to 5,10,15,20-tetrakis(2-hydroxy-5-nitrophenyl) porphyrinato iron(III). synthesis, spectroscopic and EPR characterization. Catalytic studies. J. Braz. Chem. Soc. 2008, 19, 344-351. [CrossRef]

24. Huang, G.; Xiang, F.; Li, T.; Jiang, Y.; Guo, Y. Selective oxidation of toluene over the new catalyst cobalt tetra (4-hydroxyl) phenylporphyrin supported on zinc oxide. Catal. Commun. 2011, 12, 886-889. [CrossRef]

25. Xie, Y.; Zhang, F.; Liu, P.; Hao, F.; Luo, H. Zinc oxide supported trans-CoD(p-Cl)PPCl-type metalloporphyrins catalyst for cyclohexane oxidation to cyclohexanol and cyclohexanone with high yield. Ind. Eng. Chem. Res. 2015, 54, 2425-2430. [CrossRef]

26. Dos Santos, J.S.; Faria, A.L.; Amorin, P.M.S.; Luna, F.M.L.; Caiado, K.L.; Silva, D.O.C.; Sartoratto, P.P.C.; Assis, M.D. Iron(III) porphyrin covalently supported onto magnetic amino-functionalized nanospheres as catalyst for hydrocarbon and herbicide oxidations. J. Braz. Chem. Soc. 2012, 23, 1411-1420. [CrossRef]

27. Zucca, P.; Sollai, F.; Garau, A.; Rescigno, A.; Sanjust, E. Fe(III)-5,10,15,20-Tetrakis(pentafluorophenyl)porphine supported on pyridyl-functionalized, crosslinked poly(vinyl alcohol) as a biomimetic versatile-peroxidase-like catalyst. J. Mol. Catal A Chem. 2009, 306, 89-96. [CrossRef]

28. Naik, R.; Joshi, P.; Umbarkar, S.; Deshpande, R.K. Polystyrene encapsulation of manganese porphyrins: Highly efficient catalysts for oxidation of olefins. Catal. Commun. 2005, 6, 125-129. [CrossRef]

29. Benedito, F.L.; Nakagaki, S.; Saczk, A.A.; Peralta-Zamora, P.G.; Costa, M.C.M. Study of metalloporphyrin covalently bound to silica as catalyst in the ortho-dianisidine oxidation. Appl. Catal. A Gen. 2003, 250, 1-11. [CrossRef]

30. Demel, J.; Lang, K. Layered hydroxide-porphyrin hybrid materials: Synthesis, structure, and properties. Eur. J. Inorg. Chem. 2012, 2012, 5154-5164. [CrossRef] 
31. Halma, M.; Castro, K.A.D.F.; Taviot-Gueho, C.; Prévot, V.; Forano, C.; Wypych, F.; Nakagaki, S. Synthesis, characterization, and catalytic activity of anionic iron(III) porphyrins intercalated into layered double hydroxides. J. Catal. 2008, 257, 233-243. [CrossRef]

32. Tonga, Z.; Shichia, T.; Takagi, K. Oxidation catalysis of a manganese(III)porphyrin intercalated in layered double hydroxide clays. Mater. Lett. 2003, 57, 2258-2261. [CrossRef]

33. Machado, G.S.; Wypych, F.; Nakagaki, S. Anionic iron(III) porphyrins immobilized on zinc hydroxide chloride as catalysts for heterogeneous oxidation reactions. Appl. Catal. A 2012, 413-414, 94-102. [CrossRef]

34. Machado, G.S.; Arízaga, G.G.C.; Wypych, F.; Nakagaki, S. Immobilization of anionic metalloporphyrins on zinc hydroxide nitrate and study of an unusual catalytic activity. J. Catal. 2010, 274, 130-141. [CrossRef]

35. Warmuth, W.M.; Schöllhorn, R. Progress in Intercalation Reactions; Kluver Academic Press: Oxford, UK, 1994; p. 14.

36. Mercury-Crystal Structure Visualisation, Exploration and Analysis Made Easy. Available online: http://www.ccdc.cam.ac.uk/Solutions/FreeSoftware/Pages/FreeMercury.aspx (accessed on 1 September 2015).

37. Crystallography Open Database. Available online: http://www.crystallography.net/ (accessed on 15 August 2015).

38. Drits, V.A.; Bookin, A.S. Crystal struture and X-ray identification of layered double hydroxides. In Layered Double Hydroxides: Present and Future; Rives, V., Ed.; Nova Science Publishers: New York, NY, USA, 2006; pp. 41-100.

39. Duan, X.; Evans, D.G. Layered Double Hydroxides; Springer-Verlag: Berlim, Germany, 2006; pp. 3-12.

40. Fernandes, C.I.; Vaz, P.D.; Nunes, C.D. Catalytic applications of layered double hydroxide. In Layered Double Hydroxides (LDHs): Synthesis, Characterization and Applications; Sherman, I.T., Ed.; Nova Science Publisher: New York, NY, USA, 2015; pp. 1-32.

41. Besserguenev, A.V.; Fogg, A.M.; Francis, R.J.; Price, S.J.; O’Hare, D.; Isupov, V.P.; Tolochko, B.P. Synthesis and structure of the Gibbsite intercalation compounds $\left[\mathrm{LiAl}_{2}(\mathrm{OH})_{6}\right] \mathrm{X}\left\{\mathrm{X}=\mathrm{Cl}, \mathrm{Br}, \mathrm{NO}_{3}\right\}$ and $\left[\mathrm{LiAl}_{2}(\mathrm{OH})_{6}\right] \mathrm{Cl} \cdot \mathrm{H}_{2} \mathrm{O}$ using synchrotron X-ray and neutron powder diffraction. Chem. Mater. 1997, 9, 241-247. [CrossRef]

42. Belskaya, O.B.; Baklanova, O.N.; Leont'eva, N.N.; Gulyaeva, T.I.; Likholobov, V.A. Mechanochemical synthesis of LiAl-layered hydroxides, precursors of oxidic supports and catalysts of the basic type. Procedia Eng. 2015, 113, 91-97. [CrossRef]

43. Arízaga, G.G.C.; Satyanarayana, K.G.; Wypych, F. Layered hydroxide salts: Synthesis, properties and potential applications. Solid State Ion. 2007, 178, 1143-1162. [CrossRef]

44. Satyanarayana, K.G.; Wypych, F. Clay Surfaces_Fundamentals and Applications; Academic Press: Oxford, UK, 2004; pp. 1-23.

45. Aurichalcite: Aurichalcite Mineral Information and Data. Available online: http://www.mindat.org/ min-422.html (accessed on 1 September 2015).

46. Hill, R.J. The structure of loseyite. Acta Crystallogr. 1981, B37, 1323-1328. [CrossRef]

47. Grice, J.D.; Dunn, P.J. Sclarite, a new mineral from Franklin, New Jersey, with essential octahedrally and tetrahedrally coordination zinc: Description and structure refinement. Am. Miner. 1989, 74, 1355-1359.

48. Manju, G.N.; Gigi, M.C.; Anirudhan, T.S. Hydrotalcite as adsorbent for the removal of chromium (VI) from aqueous media: Equilibrium studies. Indian J. Chem. Technol. 1999, 6, 134-141.

49. Centi, G.; Perathoner, S. Catalysis by layered materials: A review. Microporous Mesoporous Mater. 2008, 107, 3-15. [CrossRef]

50. Choy, J.H.; Choi, S.J.; Oh, J.M.; Park, T. Clay minerals and layered double hydroxides for novel biological applications. Appl. Clay Sci. 2007, 36, 122-132. [CrossRef]

51. Becker, C.M.; Gabbardo, A.D.; Wypych, F.; Amico, S.C. Mechanical and flame-retardant properties of epoxy/Mg-Al LDH composites. Composites Part A Appl. Sci. Manuf. 2011, 42, 196-202. [CrossRef]

52. Wypych, F.; Bubniak, G.A.; Halma, M.; Nakagaki, S. Exfoliation and immobilization of anionic iron porphyrin in layered double hydroxides. J. Colloid Interface Sci. 2003, 264, 203-207. [CrossRef]

53. Nakagaki, S.; Halma, M.; Bail, A.; Arízaga, G.G.C.; Wypych, F. First insight into catalytic activity of anionic iron porphyrins immobilized on exfoliated layered double hydroxides. J. Colloid Interface Sci. 2005, 281, 417-423. [CrossRef] [PubMed]

54. Liu, Y.; An, Z.; Zhao, L.; Liu, H.; He, J. Enhanced catalytic efficiency in the epoxidation of alkenes for manganese complex encapsulated in the hydrophobic interlayer region of layered double hydroxides. Ind. Eng. Chem. Res. 2013, 52, 17821-17828. [CrossRef] 
55. Kumar, P.; Gill, K.; Kumar, S.; Ganguly, S.K.; Jaina, S.L. Magnetic $\mathrm{Fe}_{3} \mathrm{O}_{4} @ \mathrm{MgAl}-\mathrm{LDH}$ composite grafted with cobalt phthalocyanine as an efficient heterogeneous catalyst for the oxidation of mercaptans. J. Mol. Catal. A Chem. 2015, 401, 48-54. [CrossRef]

56. Nakagaki, S.; Castro, K.A.D.F.; Ucoski, G.M.; Halma, M.; Prévot, V.; Forano, C.; Wypych, F. Anionic Iron(III) porphyrin immobilized on/into exfoliated macroporous layered double hydroxides as catalyst for oxidation reactions. J. Braz. Chem. Soc. 2014, 25, 2329-2338. [CrossRef]

57. Ma, J.; Liu, L.; Chen, Y.; Zhuo, M.; Shao, F.; Gonga, J.; Tong, Z. Facile assembly for fast construction of intercalation hybrids of layered double hydroxides with anionic metalloporphyrin. Dalton Trans. 2014, 43, 9909-9915. [CrossRef] [PubMed]

58. Teramura, K.; Tsuneoka, H.; Ogura, K.; Sugimoto, T.; Shishido, T.; Tanaka, T. Photoactivation of molecular oxygen by an Iron(III) porphyrin with a magnesium aluminum layered double hydroxide for the aerobic epoxidation of cyclohexene. ChemCatChem 2014, 6, 2276-2281. [CrossRef]

59. Zhan, T.; Yang, Q.; Zhang, Y.; Wang, X.; Xu, J.; Hou, W. Structural characterization and electrocatalytic application of hemoglobin immobilized in layered double hydroxides modified with hydroxyl functionalized ionic liquid. J. Colloid Interface Sci. 2014, 433, 49-57. [CrossRef] [PubMed]

60. Prrez-Bernal, M.E.; Ruano-Casero, R.; Pinnavaia, T.J. Catalytic autoxidation of 1-decanethiol by cobalt(II) phthalocyaninetetrasulfonate intercalated in a layered double hydroxide. Catal. Lett. 1991, 11, 55-62. [CrossRef]

61. Chibwe, M.; Pinnavaia, T.J. Stabilization of a cobalt(II) phthalocyanine oxidation catalyst by intercalation in a layered double hydroxide host. J. Chem. Soc. Chem. Commun. 1993. [CrossRef]

62. Sun, Z.; Jin, L.; He, S.; Zhao, Y.; Wei, M.; Evans, D.G.; Duan, X. A structured catalyst based on cobalt phthalocyanine/calcined Mg-Al hydrotalcite film for the oxidation of mercaptan. Green Chem. 2012, 14, 1909-1916. [CrossRef]

63. Parida, K.M.; Baliarsingh, N.; Patra, B.S.; Das, J. Copperphthalocyanine immobilized Zn/Al LDH as photocatalyst under solar radiation for decolorization of methylene blue. J. Mol. Catal. A Chem. 2007, 267, 202-208. [CrossRef]

64. Carrado, K.A.; Forman, J.E.; Botto, R.E.; Winans, R.E. Incorporation of phthalocyanines by cationic and anionic clays via ion exchange and direct systhesis. Chem. Mater. 1993, 5, 472-478.

65. Ukrainczyk, L.; Chibwe, M.; Pinnavaia, T.J.; Boydt, S.A. ESR study of Cobalt(II) tetrakis(N-methyl-4-pyridiniumy1)porphyrin and Cobalt(II) tetrasulfophthalocyanine intercalated in layered Aluminosilicates and a layered double hydroxide. J. Phys. Chem. 1994, 98, 2668-2676. [CrossRef]

66. Chibwe, M.; Ukrainczyk, L.; Boydt, S.A.; Pinnavaia, T.J. Catalytic properties of biomimetic metallomacrocycles intercalated in layered double hydroxides and smectite clay: The importance of edge-site access. J. Mol. Catal. A Chem. 2004, 33, 790-791. [CrossRef]

67. Ma, S.; Fan, C.; Du, L.; Huang, G.; Yang, X.; Tang, W.; Makita, Y.; Ooi, K. Intercalation of macrocyclic crown ether into well-crystallized LDH: Formation of staging structure and secondary host-guest reaction. Chem. Mater. 2009, 21, 3602-3610. [CrossRef]

68. Ma, S.; Du, L.; Wang, J.; Chu, N.; Sun, Y.; Sun, G.; Yang, X.; Ooi, K. Structural adjustment during intercalation of macrocyclic crown ether into LDH via swelling/restoration reaction: Staging formation and mechanism insights. Dalton Trans. 2011, 40, 9835-9843. [CrossRef] [PubMed]

69. Ma, S.; Wang, J.; Du, L.; Sun, Y.; Gu, Q.; Sun, G.; Yang, X. A new method for fast intercalation of bulk crown ether guest into LDH. J. Colloid Interface Sci. 2013, 393, 29-35. [CrossRef] [PubMed]

70. Sasaki, S.; Aisawa, S.; Hirahara, H.; Sasaki, A.; Narita, E. Synthesis and adsorption property of calixarene-p-sulfonate-intercalated layered double hydroxides. Chem. Lett. 2004, 33, 790-791. [CrossRef]

71. Sasaki, S.; Aisawa, S.; Hirahara, H.; Sasaki, A.; Nakayama, H.; Narita, E. Synthesis and adsorption properties of p-sulfonated calix[4 and 6]arene-intercalated layered double hydroxides. J. Solid State Chem. 2006, 179, 1129-1135. [CrossRef]

72. Stählin, W.; Oswald, H.R. The crystal structure of zinc hydroxide nitrate, $\mathrm{Zn}_{5}(\mathrm{OH})_{8}\left(\mathrm{NO}_{3}\right)_{2} \cdot 2 \mathrm{H}_{2} \mathrm{O}$. Acta Crystallogr. 1970, B26, 860-863. [CrossRef]

73. Stählin, W.; Oswald, H.R. The topotactic reaction of zinc hydroxide nitrate with aqueous metal chloride solutions. J. Solid State Chem. 1971, 3, 256-264. [CrossRef] 
74. Arízaga, G.G.C.; Mangrich, A.S.; Wypych, F. $\mathrm{Cu}^{2+}$ ions as a paramagnetic probe to study the surface chemical modification process of layered double hydroxides and hydroxide salts with nitrate and carboxylate anions. J. Colloid Interface Sci. 2008, 320, 238-244. [CrossRef] [PubMed]

75. Xue, M.; Chitrakar, R.; Sakane, K.; Ooi, K.; Kobayashi, S.; Ohnishi, M.; Doi, A. Synthesis of ktenasite, a double hydroxide of zinc and copper, and its intercalation reaction. J. Solid State Chem. 2004, 177, 1624-1630. [CrossRef]

76. Biswick, T.; Jones, W.; Pacuła, A.; Serwick, E. Synthesis, characterization and anion exchange properties of copper, magnesium, zinc and nickel hydroxy nitrates. J. Solid State Chem. 2006, 179, 49-55. [CrossRef]

77. Wypych, F.; Arízaga, G.G.C.; Gardolinski, J.E.F.C. Intercalation and functionalization of zinc hydroxide nitrate with mono and dicarboxylic acids. J. Colloid Interface Sci. 2005, 283, 130-138. [CrossRef] [PubMed]

78. Marangoni, R.; Ramos, L.P.; Wypych, F. New multifunctional materials obtained by the intercalation of anionic dyes into layered zinc hydroxide nitrate followed by dispersion into poly(vinyl alcohol) (PVA). J. Colloid Interface Sci. 2009, 330, 303-309. [CrossRef] [PubMed]

79. Demel, J.; Kubát, P.; Jirka, I.; Kovář, P.; Pospíšil, M.; Lang, K. Inorganic-organic hybrid materials: Layered zinc hydroxide salts with intercalated porphyrin sensitizers. J. Phys. Chem. C 2010, 114, 16321-16328. [CrossRef]

80. Cordeiro, C.S.; Arizaga, G.G.C.; Ramos, L.P.; Wypych, F. A new zinc hydroxide nitrate heterogeneous catalyst for the esterification of free fatty acids and the transesterification of vegetable oils. Catal. Commun. 2008, 9 , 2140-2143. [CrossRef]

81. Dolphin, D.; Traylor, T.G.; Xie, L.Y. Polyhaloporphyrins: Unusual ligands for metals and metal-catalyzed oxidations. Acc. Chem. Res. 1997, 30, 251-259. [CrossRef]

82. Groves, J.T. High-valent iron in chemical and biological oxidations. J. Inorg. Biochem. 2006, 100, $434-447$. [CrossRef] [PubMed]

83. Nam, W. High-valent iron(IV)-oxo complexes of heme and non-heme ligands in oxygenation reactions. Acc. Chem. Res. 2007, 40, 522-531. [CrossRef] [PubMed]

84. Machado, G.S.; Ucoski, G.M.; Lima, O.J.; Ciuffi, K.J.; Wypych, F.; Nakagaki, S. Cationic and anionic metalloporphyrins simultaneously immobilized onto raw halloysite nanoscrolls catalyze oxidation reactions. Appl. Catal. A 2013, 460-461, 124-131. [CrossRef]

85. Machado, G.S.; Wypych, F.; Nakagaki, S. Immobilization of anionic iron(III) porphyrins onto in situ obtained zinc oxide. J. Colloid Interface Sci. 2012, 377, 379-386. [CrossRef] [PubMed]

86. Sigoli, F.A.; Davolos, M.R.; Jafelicci, M., Jr. Morphological evolution of zinc oxide originating from zinc hydroxide carbonate. J. Alloys Compd. 1997, 262-263, 292-205. [CrossRef]

87. Fah, C.P.; Xue, J.; Wang, J. Nanosized zinc-oxide particles derived from mechanical activation of $\mathrm{Zn}_{5}\left(\mathrm{NO}_{3}\right)_{2}(\mathrm{OH})_{8} \cdot 2 \mathrm{H}_{2} \mathrm{O}$ in sodium chloride. J. Am. Ceram. Soc. 2002, 85, 273-275. [CrossRef]

88. Machovsky, M.; Kuritka, I.; Sedlak, J.; Pastorek, M. Hexagonal ZnO porous plates prepared from microwave synthesized layered zinc hydroxide sulphate via thermal decomposition. Mater. Res. Bull. 2013, 48, 4002-4007. [CrossRef]

89. Li, X.; He, G.; Xiao, G.; Liu, H.; Wang, M. Synthesis and morphology control of ZnO nanostructures in microemulsions. J. Colloid Interface Sci. 2009, 333, 465-473. [CrossRef] [PubMed]

90. Musić, S.; Dragčević, D.; Popović, S. Influence of synthesis route on the formation of ZnO particles and their morphologies. J. Alloys Compd. 2007, 429, 242-249. [CrossRef]

91. Huang, G.; Mo, L.; Cai, J.; Cao, X.; Peng, Y.; Guo, Y.; Wei, S. Environmentally friendly and efficient catalysis of cyclohexane oxidation by iron meso-tetrakis(pentafluorophenyl)porphyrin immobilized on zinc oxide. Appl. Catal. B 2015, 162, 364-371. [CrossRef]

92. Li, X.; Cheng, Y.; Kanga, S.; Mu, J. Preparation and enhanced visible light-driven catalytic activity of ZnO microrods sensitized by porphyrin heteroaggregate. Appl. Surf. Sci. 2010, 256, 6705-6709. [CrossRef]

93. De Roy, A.; Forano, C.; Malki, K.E.; Besse, J.P. Anionic clays: Trends in pillaring chemistry. In Expanded Clays and Others Micropourous Solids, 2nd ed.; Occelli, M.L., Robson, H.E., Eds.; Springer: New York, NY, USA, 1992; Volume 2, pp. 108-167.

94. Cavani, F.; Trifirò, F.; Vaccari, A. Hydrotalcite-type anionic clays: Preparation, properties and applications. Catal. Today 1991, 11, 173-301. [CrossRef]

95. De Roy, A.; Forano, C.; Besse, J.P. Layered double hydroxides: Systhesis and post-synthesis modification. In Layered Double Hydroxides: Present and Future; Rives, V., Ed.; Nova Science Publishers: New York, NY, USA, 2006; pp. 1-37. 
96. Nakamoto, K. Infrared and Raman Spectra of Inorganic and Coordination Compounds Part B, 6th ed.; John Wiley \& Sons: New York, NY, USA, 2009; pp. 91-94.

97. Conterosito, E.; Croce, G.; Palin, L.; Pagano, C.; Perioli, L.; Viterbo, D.; Boccaleri, E.; Paul, G.; Milanesio, M. Structural characterization and thermal and chemical stability of bioactive molecule-hydrotalcite (LDH) nanocomposites. Phys. Chem. Chem. Phys. 2013, 15, 13418-13433. [CrossRef] [PubMed]

98. Conterosito, E.; Palin, L.; Antonioli, D.; Viterbo, D.; Mugnaioli, E.; Kolb, U.; Perioli, L.; Milanesio, M.; Gianotti, V. Structural characterisation of complex layered double hydroxides and TGA-GC-MS study on thermal response and carbonate contamination in nitrate- and organic-exchanged hydrotalcites. Chem. Eur. J. 2015, 21, 14975-14986. [CrossRef] [PubMed]

99. Constantino, V.R.L.; Pinnavaia, T.J. Basic properties of $\mathrm{Mg}^{2+}{ }_{1-x} \mathrm{Al}^{3+}{ }_{x}$ layered double hydroxides intercalated by carbonate, hydroxide, chloride, and sulfate anions. Inorg. Chem. 1995, 34, 883-892. [CrossRef]

100. Li, L.; Dou, L.; Zhang, H. Layered double hydroxide supported gold nanoclusters by glutathione-capped Au nanoclusters precursor method for highly efficient aerobic oxidation of alcohols. Nanoscale 2014, 6, 3753-3763. [CrossRef] [PubMed]

101. Sun, Z.; Jin, L.; Zhao, Y.; He, S.; Li, S.; Wei, M.; Wang, L. A structured catalyst toward mercaptan sweetening with largely enhanced synergistic effect. Ind. Eng. Chem. Res. 2014, 53, 4595-4603. [CrossRef]

102. Schiavon, M.A.; Iamamoto, Y.; Nascimento, O.R.; Assis, M.D. Catalytic activity of nitro- and carboxy-substituted iron porphyrins in hydrocarbon oxidation Homogeneous solution and supported systems. J. Mol. Catal. A Chem. 2001, 174, 213-222. [CrossRef]

103. Machado, G.S.; Groszewicz, P.B.; Castro, K.A.D.F.; Wypych, F.; Nakagaki, S. Catalysts for heterogeneous oxidation reaction based on metalloporphyrins immobilized on kaolinite modified with triethanolamine. J. Colloid Interface Sci. 2012, 374, 278-286. [CrossRef] [PubMed]

(C) 2016 by the authors; licensee MDPI, Basel, Switzerland. This article is an open access article distributed under the terms and conditions of the Creative Commons by Attribution (CC-BY) license (http:/ / creativecommons.org/licenses/by/4.0/). 